\title{
The determinants of regional migration in Great Britain: a duration approach
}

\author{
Martyn Andrews, \\ University of Manchester, UK \\ Ken Clark \\ University of Manchester, UK, and Institute for the Study of Labor, Bonn, Germany \\ and William Whittaker \\ University of Manchester, UK
}

[Received October 2008. Final revision March 2010]

\begin{abstract}
Summary. Using the British Household Panel Survey 1990-2007, we estimate a discrete duration model of interregional migration in Great Britain. By exploiting retrospective information on residency we control for late entry as well as unobserved heterogeneity. We find considerable duration dependence in region of residence in the raw data, much of which disappears when controlling for observable and unobservable differences between individuals. We illustrate that the usual way of modelling the effect of regional variables on the propensity to migrate gives insignificant and unrobust results and we introduce a new competing risks technique.
\end{abstract}

Keywords: Duration; Hazard; Migration; Panel data; Regional labour markets

\section{Introduction}

Persistent disparities in economic performance between geographic regions of Britain have long been a focus for academic researchers and policy makers. Originally couched in terms of a 'north-south divide', the idea that place is an important determinant of labour market success, and hence welfare, is now widely accepted. The persistence, and perceived injustice, of such differentials provides a rationale for regional policy targeted at deprived areas. From the perspective of textbook economic theory, however, the persistence of interregional differences in labour market outcomes is a puzzle. Labour migration ought to provide a mechanism through which the relocation of rational workers in the pursuit of the highest possible expected earnings bids away differences in labour market outcomes. In other words, workers will be attracted to high wage regions, increasing the supply of labour, which puts downward pressure on wages. Understanding regional economic differentials therefore requires that we understand the processes that cause workers to move across regional boundaries.

Previous statistical research on internal migration in Britain has largely been based on the analysis of cross-sectional data sets where a regional migration is observed if a respondent reports a change in region of residence over the preceding year. It has been found that males, those without children, the better educated and younger generations are consistently more

Address for correspondence: Martyn Andrews, School of Social Sciences, University of Manchester, Oxford Road, Manchester, M13 9PL, UK.

E-mail: martyn.andrews@manchester.ac.uk 
mobile whereas housing constraints faced by council tenants and mortgage holders hinder migration (Hughes and McCormick, 1981, 1985). There has been conflicting evidence on the effects of regional differences in unemployment: Pissarides and Wadsworth (1989) found that unemployment discourages migration whereas Boheim and Taylor (2002) found the opposite. There is little consensus on the effect of other regional labour market variables, such as tightness of labour market, which is defined as the ratio of unfilled vacancies to workers seeking jobs, and house prices, on migration rates (Pissarides and Wadsworth, 1989; Jackman and Savouri, 1992; Hughes and McCormick, 1994; McCormick, 1997).

The use of data from a cross-section ignores the fact that a regional migration represents the termination of a continuous spell of residence in a particular region, a spell which will be of varying length for each individual. Indeed, the duration of stay in a particular region may provide an additional causal effect on the likelihood of migrating. That is to say, those who have resided in a particular region for a long time may be more or less likely to migrate than otherwise identical individuals with shorter durations of residence. This 'duration dependence' has potential implications for policy: a high degree of inertia in residential location will tend to reduce labour market flexibility.

In this paper we provide a statistical model of this process by using data from the British Household Panel Survey (BHPS), 1991-2007 (British Household Panel Survey, 2006). See Taylor et al. (2009) for full details. More specifically we estimate, for the first time using British data, a discrete time duration model of interregional migration. In other words, we model the probability that an individual migrates to another region in a given year. Because the data record how long an individual has already been at their current address when they first are observed in, or 'enter', the data, our methodology takes into account this 'delayed entry'. As is standard in the literature, we control for the effect of unobserved individual heterogeneity, namely that individuals are different from each other in ways that are not recorded in the data. As is well known, ignoring this heterogeneity leads to spurious estimates of the degree of duration dependence. Uniquely in the migration literature, we model how interregional differences in labour market outcomes affect the migration decision by using a 'competing risks' model. We divide migrations into two types: those to regions with a higher real wage and those to regions with a lower real wage. These represent two competing possibilities for individuals who are 'at risk' of migration. We then model whether the determinants of one 'risk' are different from the determinants of the other risk. Finally, to establish the robustness of our results, we compare the estimates of our model of regional migration with the estimates of a model of residential relocation between much smaller geographical units, namely local authority districts.

The remainder of the paper is structured as follows. In Section 2 we describe how we use individual level data in the BHPS to construct spells of residence in a given region, from which we construct our dependent variable. In Section 3 we present our methodology. In Section 4 we discuss our results for migrations between regions and in Section 5 we report what happens when we re-estimate our models for moves between local authority districts. Section 6 concludes the paper.

\section{The data}

The BHPS was first sampled in 1991 when 10300 individuals, in 5500 households, were interviewed across Great Britain. Households in this nationally representative sample have since been interviewed annually. The BHPS follows individuals who move residence and the extensive questionnaire on labour market and personal characteristics captures individuals' circumstances 
both before and after moving. The panel nature of the survey thus enables the construction of detailed histories for individuals.

Our definition of regional migration is based on the 11 standard statistical regions of Great Britain, as shown in Table 1. Note that here, in keeping with other analyses of regional differences in Britain (Jackman and Savouri, 1992; Pissarides and Wadsworth, 1989; Hughes and McCormick, 1994), London is merged with the South East to make it more comparable with other regions, such as the North West, which contain a metropolitan core and a less urban periphery. A regional migration is defined to have taken place when an individual changes region between one year and the next. We also analyse changes of residence between the 404 local authority districts of Great Britain. To ease terminology, we refer to the latter as 'moves' rather than 'migrations'.

Our analysis uses the first 17 waves of the BHPS (1991-2007). Throughout we analyse males and females separately. Our sample comprises the population of working age, i.e. those aged 16-64 years, who are either employed or unemployed according to standard International Labour Organisation definitions. We exclude the economically inactive, who mainly comprise the retired, the long-term sick and students, because migration for these groups is unlikely to be for labour market reasons. We also exclude those in the armed forces for the same reason. Hereafter, we refer to our sample as the economically active.

A migration occurs when an individual changes region. Because we cannot tell in a given year whether or not a migration takes place without having access to the following wave of the BHPS, effectively our sample is 1991-2006. Note that migrations include individuals who remain with their existing employer. Also, note that the sample includes both those who search and move, i.e. those who are employed when they arrive in the destination region, and those who move and search, i.e. those who are not employed when they arrive in the destination region.

Each individual is interviewed once a year at a date that varies from year to year. The data form an unbalanced panel comprising 6587 females and 6308 males observed over 49698 femaleyears and 44387 male-years. There are 1229 migrations in total. Of the 1229 migrations, 585 are by males. Since individuals may migrate more than once over the sample period, the total

Table 1. Migrations between regions $\uparrow$

\begin{tabular}{|c|c|c|c|c|c|c|c|c|c|c|c|}
\hline & $\begin{array}{c}\text { London } \\
\text { and South } \\
\text { East }\end{array}$ & $\begin{array}{c}\text { South } \\
\text { West }\end{array}$ & $\begin{array}{c}\text { East } \\
\text { Anglia }\end{array}$ & $\begin{array}{c}\text { East } \\
\text { Midlands }\end{array}$ & $\begin{array}{c}\text { West } \\
\text { Midlands }\end{array}$ & $\begin{array}{c}\text { North } \\
\text { West }\end{array}$ & $\begin{array}{c}\text { Yorkshire } \\
\text { and } \\
\text { Humber }\end{array}$ & $\begin{array}{c}\text { North } \\
\text { East }\end{array}$ & Wales & Scotland & Total \\
\hline $\begin{array}{l}\text { London and } \\
\text { South East }\end{array}$ & & 99 & 59 & 65 & 31 & 25 & 24 & 8 & 30 & 22 & 363 \\
\hline South West & 62 & & 2 & 12 & 23 & 12 & 9 & 7 & 16 & 3 & 146 \\
\hline East Anglia & 39 & 3 & & 14 & 3 & 0 & 2 & 1 & 5 & 2 & 69 \\
\hline East Midlands & 55 & 4 & 13 & & 16 & 4 & 20 & 3 & 3 & 6 & 124 \\
\hline West Midlands & 38 & 16 & 3 & 22 & & 13 & 2 & 0 & 9 & 2 & 105 \\
\hline North West & 28 & 8 & 0 & 19 & 16 & & 16 & 8 & 20 & 4 & 119 \\
\hline $\begin{array}{l}\text { Yorkshire and } \\
\text { Humber }\end{array}$ & 19 & 10 & 2 & 42 & 3 & 16 & & 18 & 10 & 2 & 122 \\
\hline North East & 17 & 12 & 1 & 9 & 2 & 12 & 19 & & 2 & 2 & 76 \\
\hline Wales & 17 & 8 & 1 & 1 & 2 & 4 & 1 & 0 & & 4 & 38 \\
\hline Scotland & 32 & 9 & 2 & 4 & 0 & 6 & 9 & 3 & 2 & & 67 \\
\hline Total & 307 & 169 & 83 & 188 & 96 & 92 & 102 & 48 & 97 & 47 & 1229 \\
\hline
\end{tabular}

$\dagger$ There are 99 migrations from London and the South East to the South West, etc. The data cover 17 waves of the BHPS, but migrations are recorded for 16 years: between 1991-1992, . ., 2006-2007. 
Table 2. Summary information: migration between regions

\begin{tabular}{|lrr|}
\hline & Males & Females \\
\hline & & \\
Number of migrations $(a)$ & 585 & 644 \\
Number of migrants $(b)$ & 438 & 487 \\
Sample size (person-years) $(c)$ & 44387 & 49698 \\
Sample size (persons) $(d)$ & 6308 & 6587 \\
Migration rate (person-years) $(a / c)$ & 1.32 & 1.30 \\
Migration rate $(b / d)$ & 6.94 & 7.39 \\
& & \\
Number of completed spells $(e)$ & 4448 & 4530 \\
Number of censored spells $(f)$ & 2411 & 2655 \\
Left-truncated first spell $(g)$ & 3364 & 3708 \\
Flow subsample $(h)$ & 3495 & 3477 \\
Number of spells $(e+f=g+h)$ & 6859 & 7185 \\
& & \\
\hline
\end{tabular}

number of migrations are for 925 different individuals, of whom 438 are male. For males these convert to an ever-migration rate of $6.94 \%$ and an average annual migration rate of $1.32 \%$. Fuller details of these figures and rates are shown in first six rows of Table 2 . We can think of the migration rate as an estimate of the 'raw hazard', i.e. the probability that a male migrates during any year. The equivalent numbers are $7.39 \%$ and $1.30 \%$ for females. These migration rates are lower than those found in previous studies, which analyse moves between the much smaller local authority districts (see Section 5 below).

In Table 1, we can see the number of migrations between regions. These occur more often between neighbouring regions and more often in and out of regions with larger populations; for the latter, compare, for example, London and the South East with Scotland.

In general, a 'spell' is defined as all the integer years that an individual resides in a given region; another spell begins if the individual migrates to another region. To be more precise, recall that our sample from the BHPS comprises the economically active. For many individuals, the start of their first spell is when they become 16 years old or complete their education, whichever is later. Some members of the sample become economically active for the first time in 1991. For these individuals we define $\underline{a}_{i 1}=1$, where in general $\underline{a}_{i 1}$ denotes the elapsed duration of individual $i$ 's first spell when first observed in the BHPS. Economically active individuals can also join the sample in subsequent years, and for these also $\underline{a}_{i 1}=1$. First spells for individuals for whom $\underline{a}_{i 1}=1$ contribute to what is called the 'flow subsample' of spells. This flow subsample also includes additional spells started by a migration to another region by individuals after 1991 .

There is also a 'stock subsample' of first spells of those individuals who were in the sample in 1991, excluding those for whom $\underline{a}_{i 1}=1$ as described above. Members of this stock subsample are said to be 'left truncated' and the individuals involved suffer 'late entry', referring to the fact that the BHPS started in 1991, which is later than these individuals' 'entry' into their first spell. Of 6308 males and 6587 females, 3364 males and 3708 females have left-truncated first spells.

Moreover, in their initial interview, respondents are asked how long they have resided at their current address. This information is crucial to our analysis. There are two distinct cases. The first comprises individuals who have not reported any change of current address since they became economically active. Here $\underline{a}_{i 1}$ records, in 1991, the number of years since they became economically active. The second subsample comprises individuals who have reported a change of current address since they became economically active. Here, $\underline{a}_{i 1}$ records, in 1991, the number of years at the current address. Because individuals can change address without migrating, 
here $\underline{a}_{i 1}$ is left censored in that the true duration in the current region may be larger than the observed duration. We emphasize that this is much better than not knowing how long individuals have resided at their current address.

In principle, the statistical methodology below needs to distinguish between these two subsamples of spells, the left-truncated subsample with $\underline{a}_{i 1}>1$ and the flow subsample with $\underline{a}_{i 1}=1$. The bottom panel of Table 2 gives full information on the numbers of spells in these subsamples. The unit of observation in our analysis is a spell, and we note that there may be more than one per individual. Table 2 shows that there are 14404 spells in the data, giving the average number of spells per individual as $14404 / 12895=1.12$. Although this discussion relates to spells as observational units, we note that the models that are analysed below will analyse data for lower level units than spells, namely the constituent periods of 1 year within those spells.

There are three reasons why spells end: an individual can migrate, an individual can leave the sample or the spell is right censored in 2006. Leaving the sample is called 'attrition' and occurs either because an individual becomes economically inactive - e.g. retires or dies — or leaves the BHPS. In the data, for males there are 2411 censored spells and 4448 completed spells, the latter including spells completed by attrition or migration. There are 585 migrations. For females, there are 2655 censored spells, 4530 completed spells and 644 migrations.

The duration of the individual's first spell is denoted $a_{i 1}$. In general, the completed duration of the $s$ th spell is $a_{i s}$. For all spells that belong to the flow subsample, $a_{i s}$ also records the number of years that the spell is observed in the BHPS. The distinction between the duration of a spell and the duration of a spell in the BHPS becomes important for the stock subsample, where the latter is computed as $a_{i 1}-\underline{a}_{i 1}+1$ and is not the same as $a_{i 1}$ when $\underline{a}_{i 1}>1$.

To illustrate the diversity of individual migration histories, Fig. 1 gives six stylized examples. The first three individuals have left-truncated first spells. The other three are new to the labour force, with the fourth individual starting in 1991 and the remaining two later than that. Completion of a spell by attrition or right censoring is denoted by ' $\circ$ ' and migration is denoted by a ' $\bullet$ '. Of the six individuals in Fig. 1, three have their final spells ended by right censoring, in 2006; for two more, their final spells end with attrition; and the remaining spell ends with a migration. Of the remaining spells in Fig. 1, all except one end with a migration. This is the first spell of the third case of a mature migrating student, which we discuss below. Fig. 1 shows why we cannot use wave 17 of the BHPS. All spells that survive to 2007 are necessarily right censored; without any variation in a spell's outcome, the 2007 data do not provide any useful information.

Fig. 1 also records a dummy variable $m_{i s}$ for whether a migration occurs or not, as well as $a_{i s}$ and $\underline{a}_{i s}$ for each spell, although the subscript $i$ is dropped for ease of presentation. From these, the reader can easily verify that the number of years that individual $i$ is observed in spell $s$ in the BHPS is given by $M_{i s} \equiv a_{i s}-\underline{a}_{i s}+1$. This is true whether or not the spell is interrupted for reasons that we discuss shortly for the case of the fifth individual. For example, the fourth individual's first spell starts in 1991, and finishes in 1992, and so $\underline{a}_{i 1}=1, a_{i 1}=2$ and the number of years the first spell is observed in the BHPS is $2\left(a_{i 1}-\underline{a}_{i 1}+1=2\right)$. Contrast this with the second individual, whose first spell starts in 1981; in 1991, the elapsed duration of this spell is 11 years. The spell ended in 2002, giving a spell duration of 22 years, of which the last 12 years were observed in the BHPS.

Defining spells for mature students is potentially problematic. We have decided not to count the years that they are being educated in the recorded duration for the current spell, so that we pause the 'duration clock'. The third individual in Fig. 1 is an example. When an individual moves region during his or her studies and does not return, we reset the duration clock to the beginning for the post-education spell, but record the end of the first spell as an attrition because 


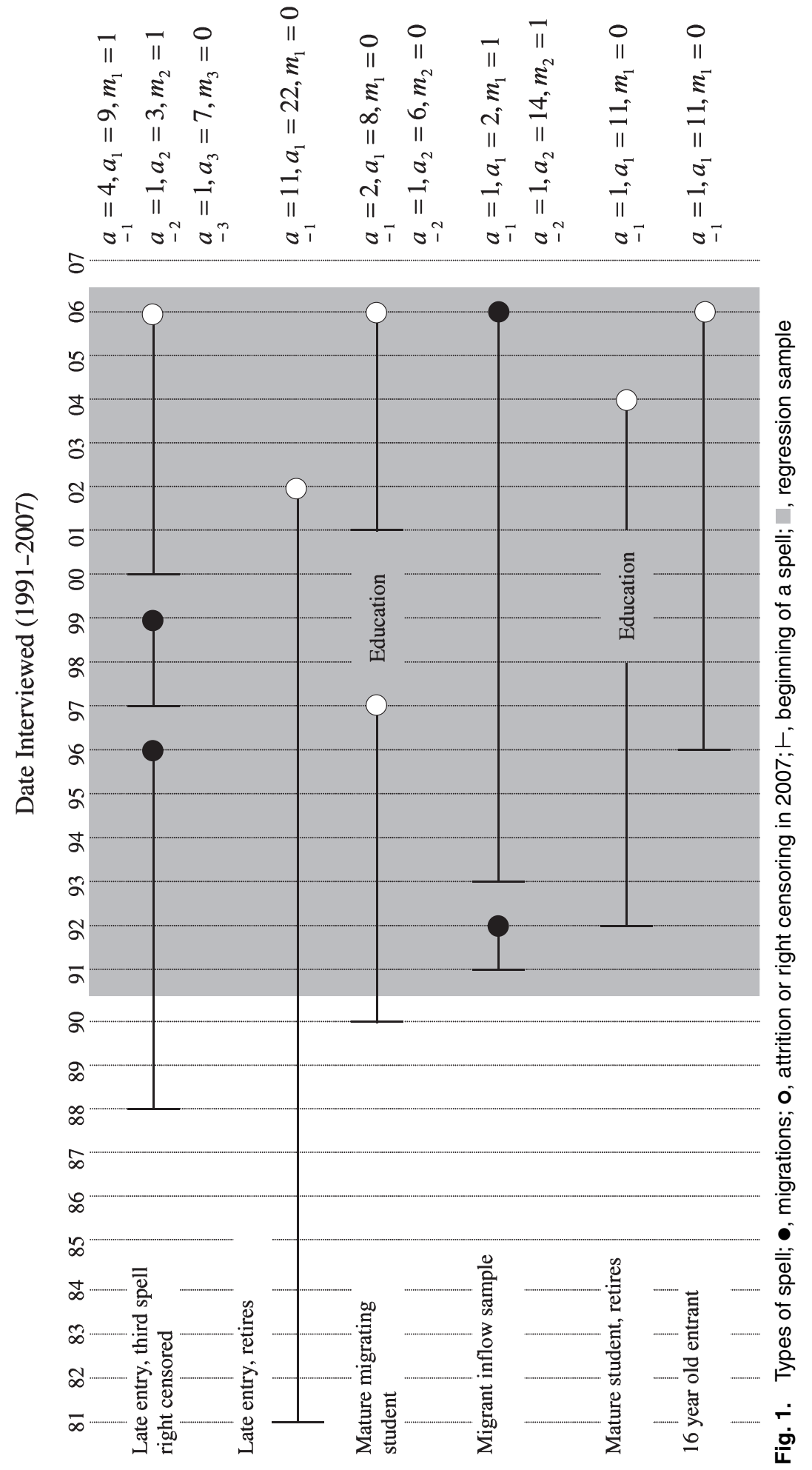


migration is for non-labour-market reasons. By contrast, the fifth individual in the Fig. 1 did not move region while studying, so we construct just one spell. The same applies to other individuals who become economically inactive.

Although attrition is a common problem with panel data, there are quite high response rates in the BHPS, being $87 \%, 90 \%$ and $95 \%$ for the first three waves respectively (Buck, 2000). However, attrition is higher among migrants: Buck gave a response rate of $72 \%$ for migrants between the first two waves. Essentially, it is more difficult for the BHPS to track respondents when they move. If there are unobserved characteristics that make migrants different from non-migrants, there is a possible sample selection issue that we can do nothing about.

To summarize, spell $s$ for individual $i$ is characterized by the following vector of time invariant information: $\left(g_{i s}, \underline{a}_{i s}, a_{i s}, m_{i s}, M_{i s}\right), s=1, \ldots, 8$, where no individual has more than eight spells in the sample. $g$ denotes the region of residence. Each spell comprises $a_{i s}-\underline{a}_{i s}+1=M_{i s}$ years of data in the BHPS, and so each individual has $M_{i}=\Sigma_{s} M_{i s}$ years of data in total. Table 3 shows how the data are constructed for the six individuals in Fig. 1.

Further, $\mathbf{x}_{i s a}$ represents all observed covariates, which can potentially vary over the elapsed duration of the spell, defined as $a$, and hence by calendar time. The covariates that are used in our analysis relate to an individual's age, housing tenure, labour market status, education, family structure, marital status and region. Two further variables based on BHPS questions on preferences are included: whether or not an individual would like to move and whether or not she likes her current area of residence. A set of year dummy variables and a set of region dummy variables are also included throughout.

One group of key covariates in all models of migration between regions is the state of the regional economy. Other things being equal, we would expect to observe net flows from 'poorer' regions to 'better' regions. To capture these regional effects, we construct a regional labour market tightness variable and the regional real wage, the latter split by gender. The tightness variable is the logarithm of the ratio of job centre vacancies (NOMISWEB, 2009) to claimant count unemployment levels (Office for National Statistics, 2009). The regional real wage rates are computed as the logarithm of the ratio of average weekly earnings (taken from the New Earnings Survey (2009) and the Annual Survey of Hours and Earnings (2009)) to the average house price level (obtained from the Halifax Building Society (2009)).

The usual way to model the effect of these covariates is to match them to the region of residence, year and gender, where appropriate. There are some problems with this. The first

Table 3. Structure of spell data in Fig. $1 \dagger$

\begin{tabular}{|rrrrrrr|}
\hline$i$ & $s$ & $g_{i s}$ & $\underline{a}_{i s}$ & $a_{i s}$ & $m_{i s}$ & $M_{i s}$ \\
\hline & & & & & & \\
1 & 1 & 7 & 4 & 9 & 1 & 6 \\
1 & 2 & 3 & 1 & 3 & 1 & 3 \\
1 & 3 & 4 & 1 & 7 & 0 & 7 \\
2 & 1 & 5 & 11 & 22 & 0 & 12 \\
3 & 1 & 1 & 2 & 8 & 0 & 7 \\
3 & 2 & 5 & 1 & 6 & 0 & 6 \\
4 & 1 & 4 & 1 & 2 & 1 & 2 \\
4 & 2 & 10 & 1 & 14 & 1 & 14 \\
5 & 1 & 6 & 1 & 11 & 0 & 11 \\
6 & 1 & 2 & 1 & 11 & 0 & 11 \\
& & & & & & \\
\hline
\end{tabular}

$\dagger$ Data correspond to Fig. 1, with arbitrary information for region of residence added. 
is that these effects are only looked at from the 'home' region perspective and do not take into consideration potential destination regions as well. For example, a region with plenty of vacancies is more likely to attract migrants compared with those which have high rates of unemployment.

The second problem arises because the model includes full sets of year and region dummy variables, as is standard. Our analysis will be on observations on years within a spell; for each region, there needs to be considerable variation of its regional covariate values over the period or else they will be effectively collinear with the regional dummy variable which is constant over spells. Similarly, unless there is considerable variation across regions within each year, the regional covariates will be collinear with year dummy variables.

The third problem is that, although time invariant unobserved regional components are swept away by the regional dummy variables, there remains the possibility that there are unobserved regional components that vary by year, reflecting time varying macroshocks that impact regions differently, or variations in regional policies. Because our two regional variables vary by both region and year, each observation does not constitute one independent piece of 'new' information because of this common regional or year unobserved random component. This is the well-known Moulton (1986) 'problem'; unless adjusted for, this clustering effect of observations means that the standard errors of estimates are biased downwards. This is another reason why the estimates on the regional variables may be uninformative.

Our approach is new in this literature. We divide spells which end with a migration, $m=1$, into two types, namely those spells where the individual moves to a region with a higher real wage $r=1$ and those spells where the individual moves to a region with a lower real wage $r=2$. Thus we have a competing risks duration model, with two exit states plus the usual right censoring state when a migration does not occur. The same approach can be used for spells where the individual migrates to and from regions with higher or lower labour market tightness.

\section{Statistical methods}

In this section, we describe the appropriate statistical methods for modelling the probability that an individual migrates in a given year, as a function of elapsed duration, and controlling for observed covariates and unobserved heterogeneity. Our data set comprises an unbalanced panel of individuals $i=1, \ldots, N$ observed annually $t=1, \ldots, 16$. There are $t_{i}$ observations for each individual. Recall that $t=1$ is wave 1 or 1991. Each individual has a number of 'spells' residing in different regions, where there are $M_{i s}$ years in spell $s$. The appropriate statistical framework is that of discrete time duration models, because an individual may migrate at any point between the date of interview in year $t$ and the day before they are interviewed in year $t+1$, but we do not observe the precise date on which this happens.

Although discrete time duration models with unobserved heterogeneity are routinely estimated, there are two features that need to be explained in this section. Wooldridge (2002) and Cameron and Trivedi (2005) are standard references on the econometrics of duration models. However, here we follow the exposition in Jenkins (2005). The first feature is that our data are left censored: recall that, for about half the individuals in the sample, we have delayed entry for their first spell, i.e. $\underline{a}_{i 1}>1$. For this, we draw heavily on Andrews et al. (2007). The second feature is using a competing risks model to investigate the effects of regional variables.

\subsection{Left truncation}

The fundamental concept in modelling migration decisions is the hazard function. The hazard 
for individual $i$ in spell $s, h_{i s a}$, is defined as the probability that an individual migrates at elapsed duration $a$, conditional on having survived to elapsed duration $a-1$ :

$$
h_{i s a} \equiv h_{a}\left(\mathbf{x}_{i s a}, u_{i}\right)=\operatorname{Pr}\left(A_{i}=a \mid A_{i} \geqslant a\right)=f_{a}\left(\mathbf{x}_{i s a}, u_{i}\right) / S_{a-1}\left(\mathbf{x}_{i s a}, u_{i}\right) \quad a=1,2, \ldots
$$

Here, $A_{i}$ is the latent duration in spell $s$ of individual $i, \mathbf{x}_{i s a}$ is a vector of observed covariates, $u_{i}$ is a frailty term capturing all individual unobserved heterogeneity, $f_{a}\left(\mathbf{x}_{i s a}, u_{i}\right)$ is the probability of observing duration $a$ and $S_{a-1}\left(\mathbf{x}_{i s a}, u_{i}\right)$ is the probability of surviving to duration $a-1$.

To start, consider the standard case where spells are observed from when individuals 'enter' the BHPS in 1991 or later, but for some there is right censoring. There are 3495 male spells and 3477 female spells in this flow subsample. The contribution to the log-likelihood function for this subsample is given by (Jenkins (2005), equation (6.9))

$$
\log (L)=\sum_{i} \sum_{s} \log \left[\left\{\frac{h_{a_{i s}}\left(\mathbf{x}_{i s a}, u_{i}\right)}{1-h_{a_{i s}}\left(\mathbf{x}_{i s a}, u_{i}\right)}\right\}^{m_{i s}} \prod_{a=1}^{a_{i s}}\left\{1-h_{a}\left(\mathbf{x}_{i s a}, u_{i}\right)\right\}\right],
$$

where recall that $a_{i s}$ denotes completed duration. Also, recall that the indicator variable $m_{i s}$ equals 1 if individual $i$ migrates from spell $s$, and 0 otherwise. The contribution to the likelihood for an individual who migrates at observed duration $a_{i s}$ is $\left(1-h_{i s 1}\right)\left(1-h_{i s 2}\right) \ldots\left(1-h_{i s, a_{i s}-1}\right) h_{i s a_{i s}}$, whereas the likelihood for an individual who does not migrate at observed duration $a_{i s}$ is $\left(1-h_{i s 1}\right)\left(1-h_{i s 2}\right) \ldots\left(1-h_{i s a_{i s}}\right)$. For example, the first spell of the fourth individual in Fig. 1 has likelihood given by $\left(1-h_{411}\right)\left(1-h_{412}\right)$.

We now discuss the problem of late entry. As noted, half of our sample have left-truncated first spells and so have already been at risk of migrating for some time, depending on their duration. The implication of this is that we are more likely to observe long rather than short durations. This is a classic sample selection problem. For individuals with a left-truncated spell, the spell's contribution to the likelihood given in equation (1) needs to be divided by

$$
S_{\underline{a}_{i s}-1}=\prod_{a=1}^{\underline{a}_{i s}-1}\left\{1-h_{a}\left(\mathbf{x}_{i s a}, u_{i}\right)\right\},
$$

(where also $s=1$ ), the probability of surviving to the first period of the subsample. Because the denominator divides into the numerator (Guo, 1993; Jenkins, 2005), the contribution to the log-likelihood becomes

$$
\log (L)=\sum_{i} \sum_{s} \log \left[\left\{\frac{h_{a_{i s}}\left(\mathbf{x}_{i s a}, u_{i}\right)}{1-h_{a_{i s}}\left(\mathbf{x}_{i s a}, u_{i}\right)}\right\}^{m_{i s}} \prod_{a=\underline{a}_{i s}}^{a_{i s}}\left\{1-h_{a}\left(\mathbf{x}_{i s a}, u_{i}\right)\right\}\right] .
$$

This is the same as equation (1), except that the product term runs from the elapsed duration of a spell when an individual enters the data, not when the spell first started. For example, because the first spell for the first individual in Fig. 1 survived to wave 1 of the BHPS, her likelihood contribution is $\left(1-h_{114}\right)\left(1-h_{115}\right) \ldots\left(1-h_{119}\right)$. To summarize, this log-likelihood applies to both the subsample that has left truncation and to the flow subsample.

The standard approach for estimating this model is to expand the data so that each spell contributes $M_{i s}=a_{i s}-\underline{a}_{i s}+1$ rows of data. See Table 3 for an example. Define a binary indicator variable $y_{i s a}$ which equals 0 unless it is the last year of the spell $\left(a=a_{i s}\right)$ and the individual migrates $\left(m_{i s}=1\right)$. For the first spell of the fourth individual in Fig. 1, the spell would have two rows of data, one for each year of the spell within the BHPS sample, with $\left\{y_{411}, y_{412}\right\}$ as $\{0,1\}$. Similarly, the first spell for the first individual in Fig. 1 would have $\left\{y_{114}, \ldots, y_{119}\right\}$ as $\{0,0,0,0,0,1\}$. We can then write the log-likelihood for this sample as

$$
\log (L)=\sum_{i} \sum_{s} \sum_{a=\underline{a}_{i s}}^{a_{i s}}\left[y_{i s a} \log \left\{h_{a}\left(\mathbf{x}_{i s a}, u_{i}\right)\right\}+\left(1-y_{i s a}\right) \log \left\{1-h_{a}\left(\mathbf{x}_{i s a}, u_{i}\right)\right\}\right] .
$$


This has the same form as the likelihood for a binary dependent variable model, using an unbalanced panel, and hence can be estimated by using standard software.

To model the effect of covariates on the hazard rate, it is usual to adopt the proportional hazards assumption

$$
h(t ; \mathbf{x})=h_{0}(t) \exp (\mathbf{x} \boldsymbol{\beta}+u),
$$

where $t$ represents elapsed duration, continuously measured, and $h_{0}(t)$ is the baseline hazard. See van den Berg (2000) for a discussion of the various identification issues. Under this assumption, the discrete hazard turns out to be the complementary log-log-link function:

$$
h_{a}\left(\mathbf{x}_{i s a}, u_{i}\right)=1-\exp \left\{-\exp \left(\mathbf{x}_{i s a} \boldsymbol{\beta}+\gamma_{a}+u_{i}\right)\right\} \quad a=1, \ldots
$$

The $\gamma_{a}$-terms are interpreted as approximately the logarithm of the non-parametric piecewise linear baseline hazard, $\gamma_{a} \approx \log \left(h_{0 a}\right)$, and, in the regressions below, the $\gamma_{a}$-terms are handled as the parameters on a full set of dummy variables for elapsed duration $a=1,2, \ldots, a_{i s}$. The notation $\mathbf{x}_{i s a}$ explicitly acknowledges that the covariates may vary with elapsed duration or calendar time. Equations (20.46) and (20.47) of Wooldridge (2002) are the same as equations (4) and (5) above; Cameron and Trivedi (2005), section 17.10.1, provided the same derivation.

Using the approximation that $\log (1-h) \approx-h$, equation (5) can be written

$$
\log \left\{h_{a}\left(\mathbf{x}_{i s a}, u_{i}\right)\right\}=\mathbf{x}_{i s a} \boldsymbol{\beta}+\gamma_{a}+u_{i} \quad a=1, \ldots
$$

This means that elements of the vector $\boldsymbol{\beta}$ are interpreted in the usual way. A small change in $x_{k}$ results in a small change in the $\log$-hazard of $\beta_{k}$ if $x_{k}$ is a continuously measured covariate; if $x_{k}$ is a binary covariate, then

$$
\beta_{k}=\log \left\{h_{a}\left(x_{k}=1 ; \mathbf{x}_{i s a}, u_{i}\right)\right\}-\log \left\{h_{a}\left(x_{k}=0 ; \mathbf{x}_{i s a}, u_{i}\right)\right\},
$$

with an appropriate change in the definition of $\mathbf{x}$.

If the baseline duration is assumed to come from an underlying continuous Weibull distribution, then the baseline hazard at elapsed duration $a$ is $\alpha \lambda a^{\alpha-1}$ with $\alpha>0$ and $\lambda>0$. Now equation (5) is amended to

$$
h_{a}\left(\mathbf{x}_{i s a}, u_{i}\right)=1-\exp \left[-\exp \left\{\mathbf{x}_{i s a} \boldsymbol{\beta}+(\alpha-1) \log (a)+u_{i}\right\}\right] \quad a=1, \ldots
$$

Note that $\mathbf{x}_{i s a}$ now contains a constant, with an associated parameter in $\boldsymbol{\beta}$ equal to $\log (\alpha \lambda)$. Instead of there being a complete set of $\gamma_{a}$-values, there is a smooth function $\log (a)$ of elapsed duration. As will be discussed in Section 4.1, testing the restrictions that are imposed by this parametric distribution on the unrestricted non-parametric hazard is straightforward.

It is well known that, when the unobserved individual heterogeneity term $u_{i}$ is ignored, its effect is confounded with that of the baseline hazard, even if $u_{i}$ and the covariates $\mathbf{x}_{i s a}$ are statistically independent. Distinguishing between heterogeneity and true state dependence has a long history in the statistics literature. In the econometrics literature, typically the heterogeneity term is integrated out. There are three main choices. The first is to assume that $\log (u)$ is gamma distributed, from which a closed form solution is obtained (Meyer, 1990). Alternatively, if $u$ is normally distributed, Gaussian quadrature can be employed to approximate the normal distribution, and the unobservable is integrated out numerically. The third possibility is to use discrete mixing, as advocated by Heckman and Singer (1984). See also Cameron and Trivedi (2005) for more details. In practice, these make little difference to the estimates of the baseline hazard or the covariates, and so we use Gaussian quadrature. For example, in Stata, the appropriate command is xtcloglog y $\mathrm{x} \log$, re ( $i)$ quad (q), where the ' $q$ ' refers to the number of quadrature points. All these methods remain valid with left-truncated data, as discussed in 
Andrews et al. (2007). Finally, we note that we do not need to integrate out the individual heterogeneity term, as it is possible to treat the data as multilevel, with observations over time within individuals, and then to estimate a multilevel random-effects model. This approach is more common outside the econometrics literature; two recent applications in applied statistics are Steele et al. $(2004,2006)$. Both are examples of competing risks models, which we discuss next.

\subsection{Competing risks}

In a competing risks framework, with spells ending in a migration to either a region with a higher real wage $r=1$ or a lower real wage $r=2$, all that happens is that two hazards are estimated, $h_{r a}\left(\mathbf{x}_{i s a}, u_{r i}\right), r=1,2$. Two identical panel data sets are created, except that now $y_{r i s a}$ equals 0 unless it is the last year of the spell $\left(a=a_{i s}\right)$ and the individual migrates to risk $r$. As an example, consider the first spell of the first individual in Fig. 1. Suppose that she exits to a region with higher labour market tightness, $r=1$. In the first data set, she has six rows of data, with $\left\{y_{1114}, \ldots, y_{1119}\right\}$ as $\{0,0,0,0,0,1\}$, whereas, in the second data set, $\left\{y_{2114}, \ldots, y_{2119}\right\}=$ $\{0,0,0,0,0,0\}$. The likelihood of observing each data set is given by equation (2) (with appropriate indexing for risk $r$ ), and the hazard for risk $r$ amends equation (5) as follows:

$$
h_{r a}\left(\mathbf{x}_{i s a}, u_{r i}\right)=1-\exp \left[-\exp \left\{\mathbf{x}_{r i s a} \boldsymbol{\beta}_{r}+\left(\alpha_{r}-1\right) \log (a)+u_{r i}\right\}\right] \quad a=1, \ldots, \quad r=1,2 .
$$

When interpreting the parameter vectors $\boldsymbol{\beta}_{1}$ and $\boldsymbol{\beta}_{2}$, it is important to emphasize that neither conveys direct information about the effect of a single covariate $x$ on either the likelihood of exit via risk $r\left(\Pi_{r}\right)$, or the expected waiting time until exit via risk $r\left(E_{r}\right)$ (Lancaster, 1990; Thomas, 1996). This is because $\Pi_{r}$ (and therefore $E_{r}$ ) depends on the parameters of both $h_{1 a}$ and $h_{2 a}$ via the overall survivor function $S_{a}$. Moreover, neither $\Pi_{r}$ nor $E_{r}$ is easily estimated, as they need to be computed by numerical integration. See Appendix A for a fuller explanation.

However, a result that was provided by Thomas (1996) is particularly useful when proportional hazards are assumed. Instead of examining the effects of a particular covariate $x$ on the unconditional probability of exit, it is computationally much easier to focus on the probability of exiting to risk $r$ conditional on exiting at elapsed duration $a$. The probability of migrating to a higher wage region, given a migration, is defined as

$$
P_{2 a} \equiv \frac{h_{2 a}}{h_{1 a}+h_{2 a}} .
$$

Thus, in addition to estimates of $\beta_{1}$ and $\beta_{2}$, we report the marginal effect of a particular covariate $x$ on $P_{2 a}$, which, from equation (6), is given by

$$
\frac{\partial P_{2 a}}{\partial x}=\frac{h_{1 a} h_{2 a}\left(\beta_{2}-\beta_{1}\right)}{\left(h_{1 a}+h_{2 a}\right)^{2}} .
$$

As with the single-risk case, the same formula applies a discrete change induced by changing a dummy variable from 0 to 1 :

$$
P_{2 a}\left(x_{k}=1 ; \cdot\right)-P_{2 a}\left(x_{k}=0 ; \cdot\right)=\frac{h_{1 a} h_{2 a}\left(\beta_{2}-\beta_{1}\right)}{\left(h_{1 a}+h_{2 a}\right)^{2}} .
$$

Standard errors are obtained by computing

$$
\frac{h_{1 a} h_{2 a}}{\left(h_{1 a}+h_{2 a}\right)^{2}}\left\{\operatorname{se}\left(\beta_{1}\right)+\operatorname{se}\left(\beta_{2}\right)\right\} \text {. }
$$

How we compute $h_{1 a}$ and $h_{2 a}$ is discussed in Section 4.1 immediately below. 


\section{Results}

Estimating the migration hazard between regions allows us to address three issues. First, we estimate whether there is any genuine duration dependence in the hazard, after we control for observable and unobservable characteristics. Second, we examine whether our proposed method for modelling regional effects in a competing risks framework offers anything new relative to standard methods. Finally, we check whether the estimates of the effects of standard covariates differ from what is usually found, given that we are using longitudinal data.

\subsection{Duration dependence and the shape of the baseline hazard}

By computing the proportion of spells that end with a migration for $a=1,2,3, \ldots$, the raw hazards are generated. These are plotted in Figs 2(a) and 2(b), for males and females separately, and are labelled 'raw non-parametric'. Thus, for males, the raw hazard rate falls from 0.0298 in the first year to 0.0120 after 10 years, and to 0.0053 for durations between 16 and 20 years. For females, these hazards are $0.0316,0.0112$ and 0.0055 respectively. Clearly, the raw data exhibit migration inertia, in that the longer a person resides in a region the less likely he or she is to migrate. Said differently, the raw hazards exhibit negative duration dependence.

There are two issues. First, is this duration dependence genuine, and, second, if it is, what causes duration dependence? The first issue came to prominence in the statistics literature, when estimating unemployment duration models, because it was realized that not controlling for heterogeneity across individuals overestimates the degree of negative duration dependence (see, for example, Han and Hausman (1990)). Essentially, the sample selection effect of 'better' individuals leaving unemployment more quickly than the 'worse' individuals leads to spurious duration dependence in the observed data - the sample becomes increasingly dominated by worse individuals, whose exit rates are lower, as elapsed duration evolves. This argument applies to both observable and unobserved differences between individuals.

This paper is concerned with migration between regions - do the same issues apply? Because individuals are heterogeneous, and have different propensities to migrate, the answer is probably 'yes'. Individuals who are more likely to migrate might be labelled 'footloose' or 'dynamic', and might be younger or more educated or want to find better labour market opportunities. In contrast, there are individuals who become locked into regions as they grow older because of attachments to jobs, schools, houses etc.

In the rest of this subsection, we report what happens when we control for observable and unobservable characteristics to see whether there is any genuine duration dependence in the data. An identical way of computing the raw hazards is to estimate equation (5) without controlling for either covariates or unobserved heterogeneity. Because the shape of the raw hazard looks very similar to hazards that are drawn from a Weibull distribution, we re-estimate, replacing equation (5) by equation (8). The estimated Weibull parameter $\alpha$ is estimated as 0.372 and 0.351 for males and females respectively, and hazards labelled 'raw Weibull' are also plotted in Figs 2(a) and 2(b).

To test the Weibull specification against the unrestricted 'raw non-parametric' specification, note that the $\gamma_{a}$-parameters in equation (5) are restricted to $\alpha-1$ in equation (8) by

$$
\gamma_{a}=\log (\gamma \alpha)+(\alpha-1) \log \left(a^{\prime}\right) \quad a=1, \ldots, 17,
$$

where $a^{\prime}$ is the midpoint of each interval, rounded up to the nearest integer. These lead to the 15 linear restrictions 

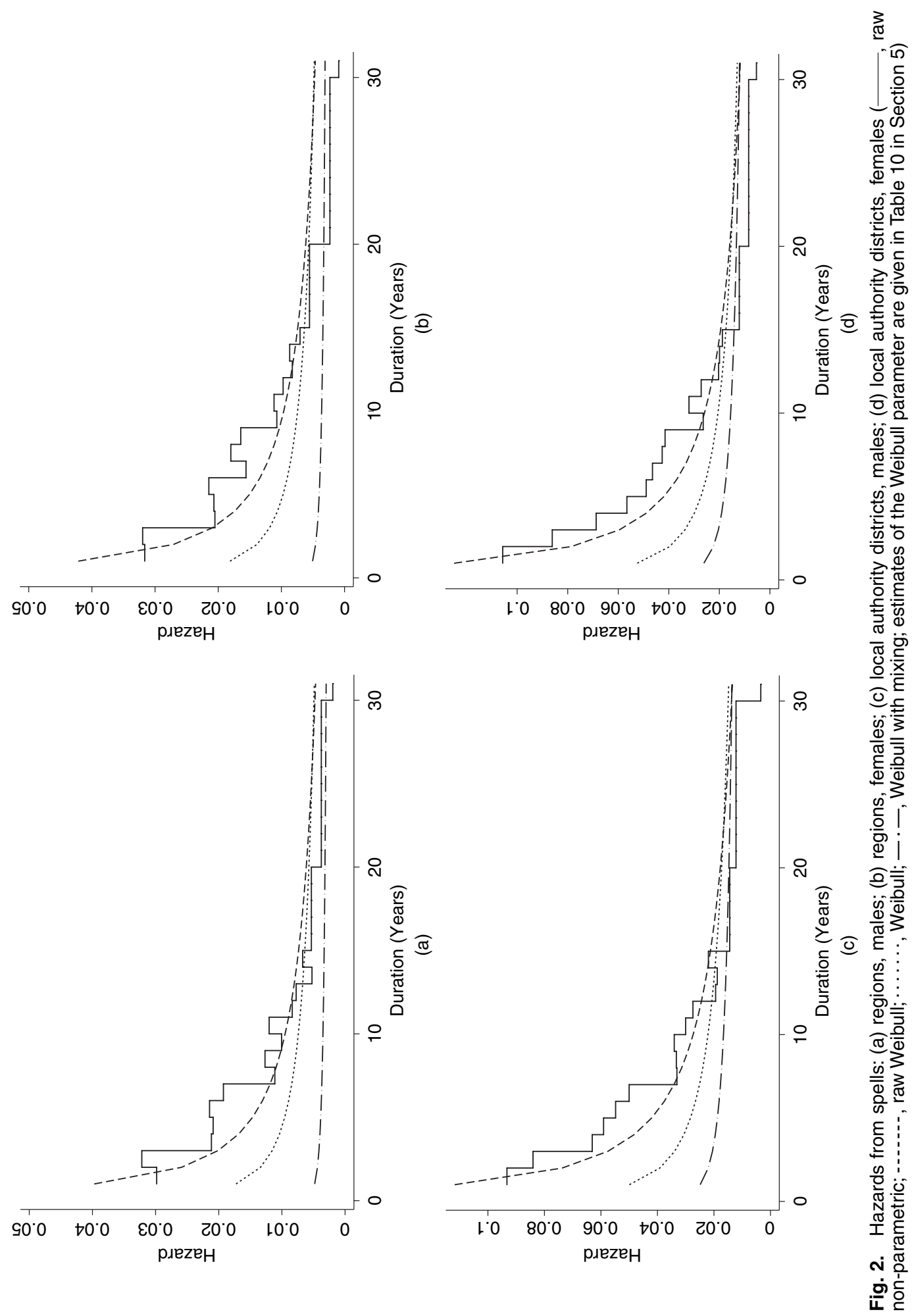


$$
\begin{gathered}
\gamma_{3}-\gamma_{2}=\frac{\log (3 / 2)}{\log (2 / 1)}\left(\gamma_{2}-\gamma_{1}\right), \\
\vdots \\
\gamma_{16}-\gamma_{15}=\frac{\log (25 / 17)}{\log (17 / 14)}\left(\gamma_{15}-\gamma_{14}\right), \\
\gamma_{17}-\gamma_{16}=\frac{\log (40 / 25)}{\log (25 / 17)}\left(\gamma_{16}-\gamma_{15}\right)
\end{gathered}
$$

These equations give the ratios of consecutive reductions in the raw hazard, and $\gamma_{a}-\gamma_{a-1}$ should become increasingly smaller if the baseline duration really is drawn from a Weibull distribution. For males, the Weibull function fits the raw data very closely as the Wald test of the 15 restrictions has a $p$-value of 0.489 . For females, we need to exclude the last two restrictions to obtain a sufficiently large $p$-value (0.556). When they are included, the $p$-value becomes 0.015 . Nonetheless, because of comparability and parsimony, for both males and females, we maintain the basic Weibull specification.

When we control for observed covariates, the estimates of the Weibull parameter increase to 0.630 and 0.610 respectively. This is as expected, as controlling for observables should reduce the degree of spurious duration dependence. These hazards, labelled 'Weibull', are also plotted in Figs 2(a) and 2(b), with the covariates evaluated at their mean values. We do not report or dwell on these estimates, as it is not our preferred specification. However, note what happens to the estimate of $\alpha$ when only age dummy variables are included in the regression. The estimates of $\alpha$ drop to 0.490 for males and 0.498 for females, which shows that age is an extremely important determinant of both migration decisions and the spurious degree of duration dependence that are observed in the raw data. Individuals are less likely to migrate as they grow older for various reasons. The first is the rising non-pecuniary migration costs that are associated with the investment in social and family networks that individuals make when they live in the same area for an extended period of time. Second, a better knowledge of the local labour market may contribute to inertia. Third, it is possible that, as individuals grow older, they become more risk averse.

We now re-estimate the two models, but controlling for individual unobserved heterogeneity. Of the three choices that were discussed, we use Gaussian mixing. Note that the individual unobserved heterogeneity term $\sigma_{u}$ is significantly different from 0 for both males and females, and so this model is our preferred specification. The estimated parameters from this model are reported in Table 4 and are discussed in Section 4.3 below.

Now the hazard becomes flatter still, with $\alpha$ estimated as 0.863 and 0.857 respectively. To see how much flatter, look at the hazards labelled 'Weibull with mixing' in Figs 2(a) and 2(b). However, both estimates are significantly different from 1 , which means that there remains genuine negative duration dependence in the observed data. We need to consider whether this duration dependence is economically significant. We calculate that the baseline hazard falls from 0.0048 after 1 year to 0.0035 after 10 years for males and from 0.0051 to 0.0036 for females. In both cases, the hazard falls by about a third, or, more precisely, using equation (7), the hazard falls by 0.318 and 0.333 log-points respectively. To put this in context, Table 4 reports that a male with General Certificates of Secondary Education is more likely to migrate than a male without formal qualifications by about 0.524 log-points; for females, the estimate is 0.463 log-points.

To conclude, the longer that individuals stay in a region, the less likely they are to migrate to another region of the UK. Furthermore, a particularly important part of this is that individuals grow older. This appears not to be well known, although Gerber (2005) found a similar negative effect on Russian internal migration, estimating $\alpha$ as 0.547 on a sample that pools males and females, whereas Detang-Dessendre and Molho $(1999,2000)$, in a study of young French men 
Table 4. Hazard to migration, Weibull baseline hazard, Gaussian mixing $\dagger$

\begin{tabular}{|c|c|c|c|c|}
\hline \multirow{2}{*}{$\begin{array}{l}\text { Variable } \\
\text { Weibull } \alpha\end{array}$} & \multicolumn{2}{|c|}{ Estimate for males } & \multicolumn{2}{|c|}{ Estimate for females } \\
\hline & 0.863 & $(0.062)$ & 0.857 & $(0.062)$ \\
\hline Age $18-19$ years & 0.425 & $(0.354)$ & 0.033 & $(0.330)$ \\
\hline Age $20-23$ years & 0.545 & $(0.331)$ & 0.120 & $(0.304)$ \\
\hline Age $24-29$ years & -0.063 & $(0.343)$ & -0.268 & $(0.311)$ \\
\hline Age $30-37$ years & -0.234 & $(0.350)$ & -0.376 & $(0.320)$ \\
\hline Age $38-49$ years & -0.528 & $(0.360)$ & -0.715 & $(0.333)$ \\
\hline Age $\geqslant 50$ years & -0.733 & $(0.392)$ & -1.060 & $(0.368)$ \\
\hline Owned with mortgage & 0.112 & $(0.167)$ & 0.071 & $(0.154)$ \\
\hline Local authority rented & 0.202 & $(0.202)$ & -0.226 & $(0.187)$ \\
\hline Private furnished & 0.519 & $(0.227)$ & 0.301 & $(0.211)$ \\
\hline Private unfurnished & 0.635 & $(0.202)$ & 0.520 & $(0.197)$ \\
\hline Employed non-manual & 0.464 & $(0.120)$ & -0.241 & $(0.127)$ \\
\hline Unemployed & 0.512 & $(0.166)$ & 0.066 & $(0.202)$ \\
\hline Maternity or family care & 1.639 & $(0.267)$ & 0.376 & $(0.145)$ \\
\hline Higher degree & 1.443 & $(0.291)$ & 1.419 & $(0.293)$ \\
\hline Degree & 1.150 & $(0.208)$ & 1.236 & $(0.187)$ \\
\hline A level & 0.842 & $(0.200)$ & 0.841 & $(0.189)$ \\
\hline General Certificates of Secondary Education & 0.524 & $(0.194)$ & 0.463 & $(0.170)$ \\
\hline 1 child & -0.204 & $(0.133)$ & -0.300 & $(0.121)$ \\
\hline 2 or 3 children & -0.032 & $(0.155)$ & -0.167 & $(0.140)$ \\
\hline$\geqslant 4$ children & -0.372 & $(0.245)$ & -0.325 & $(0.208)$ \\
\hline Like to move & 0.783 & $(0.097)$ & 0.893 & $(0.093)$ \\
\hline Like neighbourhood & -0.386 & $(0.135)$ & -0.317 & $(0.123)$ \\
\hline Spouse employed full time & -0.026 & $(0.131)$ & -0.330 & $(0.107)$ \\
\hline Spouse employed part time & -0.104 & $(0.177)$ & 0.041 & $(0.264)$ \\
\hline Spouse unemployed & 0.342 & $(0.152)$ & -0.246 & $(0.153)$ \\
\hline Constant & -4.265 & $(0.451)$ & -4.433 & $(0.412)$ \\
\hline$\sigma_{\mathrm{u}}$ & 1.294 & $(0.089)$ & 1.261 & $(0.083)$ \\
\hline & & & & 698 \\
\hline Log-likelihood & & 7.306 & & 1.768 \\
\hline
\end{tabular}

$\dagger$ Estimates of parameters $\alpha$ and $\beta$ in equation (8). $\sigma_{\mathrm{u}}$ is the estimate of the standard error of the unobserved individual heterogeneity, $u_{i} .12$ quadrature points were used in each regression. Year and region dummy variables are included in the model but estimated coefficients are not reported. Base for dummy variables: manual worker living in London and the South East in 1991, has no formal qualifications, children or spouse, owns their own house outright and is 16-17 years old. $\$$ The only economically inactive individuals whom we do not drop from the sample are those inactive for family reasons.

and women, also found a negative effect, with duration dependence being stronger among males. Negative duration dependence was also found for graduating students in Finland (Haapanen and Tervo, 2009). Finally, we find that observed covariates do not tell the whole story, as controlling for unobserved heterogeneity flattens the baseline hazard further still.

\subsection{Competing risks and aggregate regional effects}

In the first instance, we mimic the standard approach to modelling aggregate regional effects. In other words, we re-estimate the model reported in Table 4, now adding our two regional variables, $\log$ (regional real wage) and $\log ($ regional labour market tightness), to the specification. The estimates on the regional real wage are $0.330(0.546)$ for males and $-0.444(0.485)$ for females. As already noted, the standard errors are large because the two variables need to vary considerably across years and regions. The point estimates are also large, being elasticities. Not 
only are the estimates imprecisely estimated; they also take the opposite sign. The estimates on the labour market tightness variable are $0.073(0.271)$ for males and $0.108(0.262)$ for females. Again, these are both statistically insignificant.

Moreover, as already noted, these standard errors need to be inflated to account for the wellknown Moulton (1986) effect, because we have ignored a region-year unobserved effect, $\varepsilon_{g t}$. The proportional increase is known as the 'Moulton factor'. To be absolutely clear, the model being estimated is

$h_{a}\left(\mathbf{x}_{i s a}, u_{i}\right)=1-\exp \left[-\exp \left\{\mathbf{x}_{i s a} \boldsymbol{\beta}+(\alpha-1) \log (a)+\mathbf{z}_{g t} \delta+\eta_{g}+\rho_{t}+\varepsilon_{g t}+u_{i}\right\}\right] \quad a=1, \ldots$,

where the vector $\mathbf{z}_{g t}$ contains the two regional variables, $\eta_{g}$ are the coefficients on a full set of region dummy variables and $\rho_{t}$ are the coefficients on a full set of year dummy variables.

To compute the Moulton factor, we implement a suggestion of Angrist and Pischke (2009). We compute estimates of each spell's hazard, purged of the effects of $\mathbf{x}_{i s a}$. We then collapse the data to group averages, i.e. form a panel data set of 10 regions by 16 years. When regressing the hazard rate on the two regional variables, plus time and region dummy variables, the estimates on the real wage are $0.987(0.731)$ for males and $0.351(0.638)$ for females. This illustrates how unrobust the effects of the real wage variable are. The effects of labour market tightness are $0.362(0.351)$ and $0.306(0.327)$ respectively. Although more robust, the estimates remain insignificant. In all four cases, the standard errors have inflated by about 1.3 times, which we interpret as approximately the Moulton factor. Being close to 1, it is not an issue in this analysis.

In short, for both variables, very little is learned from this 'traditional' approach to modelling migrations, because there is insufficient regional and yearly variation in these variables. We now report what happens when we estimate two competing risks versions of our models.

In the first of these, the two risks are whether spells end with individuals migrating to regions with a higher or lower real wage. Of the 585 male migrations, 283 are to a region with a higher real wage. Of 644 female migrations, the corresponding number is 326 . In the second of these, the risks are whether an individual migrates to a region with a higher or lower labour market tightness, now with 311 male migrations and 344 female migrations.

Using the same specification as reported in Table 4, we estimate equation (9) twice, giving a 'regional real wage' specification and a 'regional tightness' specification. In the regional real wage specification, a test of whether the regional real wage has any effect on individuals' propensity to migrate between regions is simply whether the covariate effects in the two models are the same as each other. Testing $H_{0}: \boldsymbol{\beta}_{1}=\boldsymbol{\beta}_{2}, \alpha_{1}=\alpha_{2}$ is essentially a Chow test, but in a non-linear setting. For males, the test statistic has a $p$-value of 0.089 , whereas for females it is 0.457 . Repeating for the regional tightness specification, the $p$-values are 0.078 for males and 0.055 for females.

Because the test outcomes are marginal in three out of the four cases, there are some variables whose estimates differ by risk. For males, a selection of variables and their estimates are given in Table 5 for the regional real wage specification. One such variable is employment status. To see what is happening, we use estimates from Table 5 and evaluate the Weibull hazard at mean characteristics except for whether manual, non-manual or unemployed, whose dummy variables are switched on and off appropriately. These give

$$
h_{1}=\exp (-4.666) t^{-0.400}, \quad h_{2}=\exp (-4.467) t^{-0.346}
$$

if non-manual,

$$
h_{1}=\exp (-4.962) t^{-0.400}, \quad h_{2}=\exp (-5.156) t^{-0.346}
$$


Table 5. Competing risks models: migrating to regions with higher or lower real wages for males $\dagger$

\begin{tabular}{|lrrrrrr|}
\hline Variable & $\begin{array}{c}\text { Estimate for higher } \\
\text { wage region }\end{array}$ & \multicolumn{2}{c|}{$\begin{array}{c}\text { Estimate for lower } \\
\text { wage region }\end{array}$} & $\begin{array}{c}\text { Difference in } \\
\text { probability }\end{array}$ \\
\hline Weibull $\alpha$ & 0.654 & $(0.071)$ & 0.600 & $(0.082)$ & & \\
Age $\geqslant 50$ years & -0.205 & $(0.252)$ & -0.851 & $(0.320)$ & 0.161 & $(0.143)$ \\
Owned with mortgage & 0.050 & $(0.210)$ & 0.154 & $(0.219)$ & -0.026 & $(0.107)$ \\
Employed non-manual & 0.689 & $(0.167)$ & 0.296 & $(0.152)$ & 0.098 & $(0.080)$ \\
Unemployed & 0.574 & $(0.231)$ & 0.388 & $(0.217)$ & 0.047 & $(0.112)$ \\
Higher degree & 1.144 & $(0.346)$ & 1.460 & $(0.354)$ & -0.079 & $(0.175)$ \\
\hline
\end{tabular}

$\dagger$ Estimates of $\boldsymbol{\beta}$ for selected variables in equation (9). Without Gaussian mixing and regional dummy variables are dropped because collinear with the two dummy variables created for $r=1$ and $r=2$. Base for dummy variables: manual worker living in London or the South East in 1991, has no formal qualifications, children or spouse, owns their own house outright and is $24-29$ years old.

$\ddagger$ See equations (11) and (13). For $h_{1 a}$ and $h_{2 a}$, we illustrate for $a=5$ and use sample average migration rates.

if manual,

$$
h_{1}=\exp (-4.582) t^{-0.400}, \quad h_{2}=\exp (-4.575) t^{-0.346}
$$

if unemployed, and are plotted in Figs 3(a)-3(c). We can clearly see how the shape of the Weibull hazards affects $P_{2}$, the probability of migrating to a high wage region, given migration, as defined in equation (10), compared with migrating to a low wage region. A male non-manual worker who migrates is more likely to migrate to a higher wage region rather than a lower wage region, but it is the other way round for manual workers (Figs 3(a) and 3(b)). As shown in Fig. 3(d), at elapsed duration of $t=5$ years in the current region, $P_{2}=0.571$ for male non-manual workers, 0.473 for manual workers and 0.523 for the male unemployed. The difference in the probabilities between manual and non-manual is 0.098 probability points, as reported in Table 5 . Although 0.098 is economically significant, it is not statistically significant, with a standard error of 0.080 . Note that manual workers have a lower hazard than non-manual workers and the unemployed, but the ranking between the latter two categories depends on which type of region. This is seen in the coefficient estimates that are also reported in Table 5. Also, Fig. 3(d) shows that choosing $a=5$ to evaluate $P_{2}$ is innocuous.

Although we have not tabulated results for women, a very similar estimate occurs for the contrast between manual and non-manual, with the difference in probability being $0.072(0.082)$. In passing, it is worth noting that earlier studies such as Hughes and McCormick (1994) found that manual workers have lower migration rates, because they are more likely to have more industryspecific, and thus potentially regional-specific, skills than non-manual workers. In contrast, non-manual workers are more likely to have general transferable skills (Evans and McCormick, 1994). Further, Hughes and McCormick (1994) argued that, because manual workers are less responsive to regional wages, manual wages are more inflexible than non-manual wages. In Table 6, we repeat the exercise for the regional tightness specification, for males. It is easy to see that a similar pattern emerges, even though the actual estimates differ, because migrating to a low wage region is not the same as migrating to a region with relatively few vacancies.

To conclude this subsection, we reaffirm that the traditional way of adding regional covariates that measure the state of the regional labour market has no influence whatsoever on individual migration decisions. Using a novel competing risks technique, which compares the home and destination regions for migrants, we again find little evidence that regional variables have an 

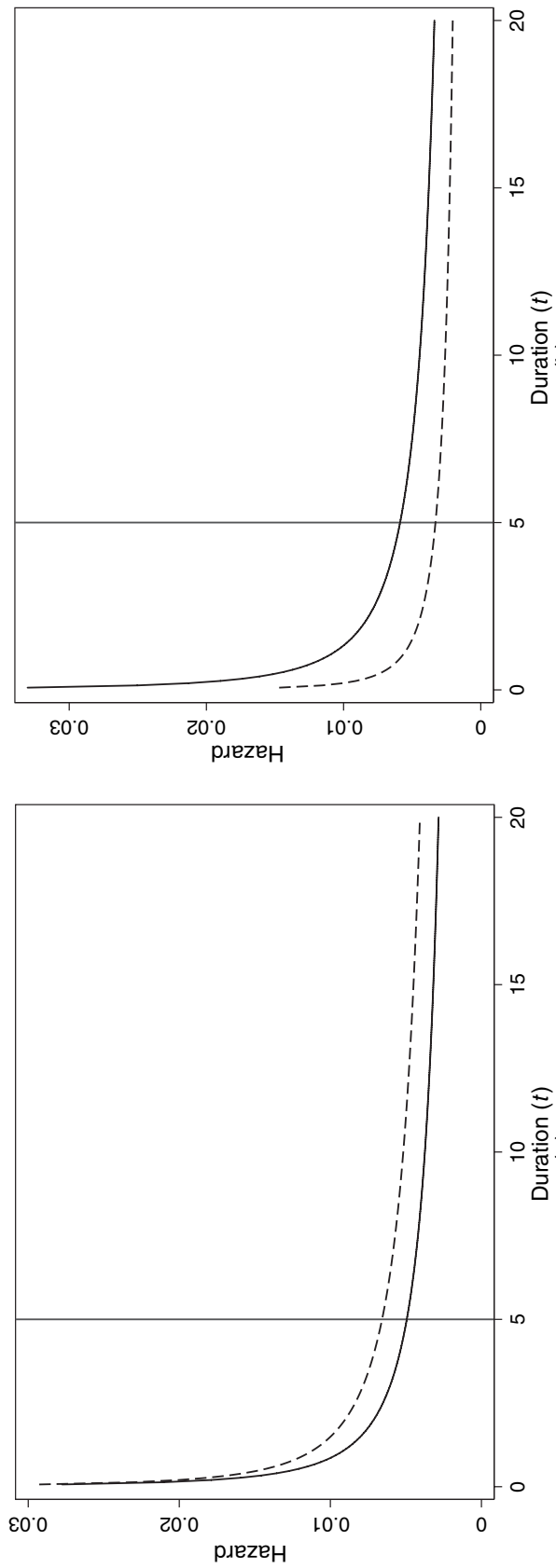
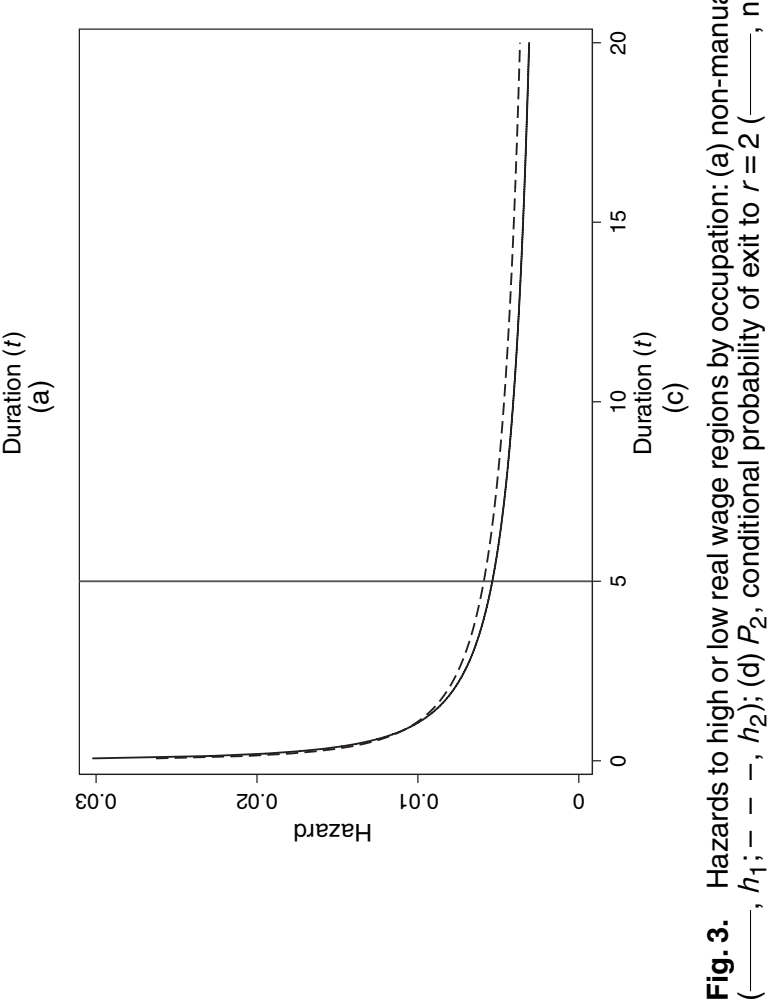
Table 6. Competing risks models: migrating to regions with higher or lower labour market tightness for males $\dagger$

\begin{tabular}{|c|c|c|c|c|c|c|}
\hline \multirow{2}{*}{$\begin{array}{l}\text { Variable } \\
\text { Weibull } \alpha\end{array}$} & \multicolumn{2}{|c|}{$\begin{array}{l}\text { Estimate for higher } \\
\text { tightness region }\end{array}$} & \multicolumn{2}{|c|}{$\begin{array}{l}\text { Estimate for lower } \\
\text { tightness region }\end{array}$} & \multicolumn{2}{|c|}{$\begin{array}{l}\text { Difference in } \\
\text { probability }\end{array}$} \\
\hline & 0.640 & $(0.071)$ & 0.614 & $(0.082)$ & & \\
\hline Age $\geqslant 50$ years & -0.446 & $(0.500)$ & -0.179 & $(0.555)$ & -0.067 & $(0.264)$ \\
\hline Owned with mortgage & -0.169 & $(0.200)$ & 0.429 & $(0.233)$ & -0.149 & $(0.108)$ \\
\hline Employed non-manual & 0.516 & $(0.152)$ & 0.458 & $(0.167)$ & 0.014 & $(0.080)$ \\
\hline Unemployed & 0.457 & $(0.218)$ & 0.499 & $(0.229)$ & -0.011 & $(0.112)$ \\
\hline Higher degree & 1.380 & $(0.322)$ & 1.188 & $(0.387)$ & 0.048 & $(0.177)$ \\
\hline
\end{tabular}

$\dagger$ See the footnotes to Table 5 .

effect, although there are some characteristics that are almost significant, e.g. whether individuals - but more so for males - have a manual or non-manual occupation.

\subsection{Other covariates}

The results in Table 4 identify which individuals are more likely to migrate. In other words, we can establish which covariates shift the baseline hazard and in what direction. To make sure that there are statistically significant influences on the likelihood of migration, we take each of the age, housing tenure, education, employment status and family structure variables and in turn perform separate simultaneous tests of the set of dummy variables corresponding to them. It turns out that each block has a $p$-value of 0.000 except for the children variables, being 0.243 and 0.077 for males and females respectively, and the spouse variables, being 0.020 and 0.013 respectively. In this subsection, we briefly discuss some of these effects.

Some of these influences are similar to findings from the existing literature on the UK, largely based on cross-sections of households or individuals, some of whom have migrated. Thus, previous studies do not control for duration dependence or unobserved individual heterogeneity. In common with other studies (e.g. Hughes and McCormick (1981), Pissarides and Wadsworth (1989) and Boheim and Taylor (2002)) we note that, as previously discussed, age has a strong negative effect on migration: this is particularly pronounced for men and women in their 40s and older. We also reproduce the findings of, for example, Hughes and McCormick (1981, 1985) and Coleman and Salt (1992), that better educated individuals are more likely to migrate. Indeed, in terms of economic and statistical significance, these are some of the strongest effects in Table 4 - a clear, monotonic relationship between level of qualification and the probability of migrating is found. A man with a higher degree is $1.443-0.524=0.919$ log-points more likely to migrate than a man with just General Certificates of Secondary Education. (1.443 and 0.524 refer to the coefficient estimates on the two variables.) The equivalent figure for females is 0.956 log-points. Faggian et al. (2007) suggested that women graduates are more mobile than their male counterparts as a way of compensating for gender discrimination in the labour market; however, there are no significant differences between men and women in our data.

The effect of housing tenure on labour migration has been a focus of research in the UK-it has been variously argued that those in social housing and mortgage holders are less mobile than other groups (Hughes and McCormick, 1981; Oswald, 1997). Our results suggest, in line with previous work, that those renting from a private landlord are the most likely to migrate, which reflects the lower cost of moving for such individuals. In contrast with other studies, however, we find very little difference in the propensity to migrate between local authority tenants, 
mortgage holders and those who own their homes outright. Many changes have taken place in the housing market over the sample period. There have been years of rapidly increasing house prices as well as years in which there have been high levels of repossessions - both of which it could be argued reduce the mobility of mortgage holders.

Our decision to estimate separate models by gender, which is an uncommon practice in the literature, is vindicated by the results in Table 4 . Whereas the effects of education and age are broadly similar for men and women, variables relating to employment status, children and spouse's occupation display some interesting differences. For example, unemployed men are predicted to be more likely to migrate than the excluded category of manual workers (Pissarides and Wadsworth, 1989). There is no such effect for women. This may suggest that womens' migrations are 'tied' to the decision of the males in their households, particularly since having a spouse employed full time significantly reduces the likelihood that a woman will migrate. The presence of children in the household is estimated to reduce the probability of migrating for men and women with the magnitude of the effect dependent on the ages of the children. However, the children variables are only significant for women.

Finally, some variables in the BHPS are designed to measure the attitudes of respondents to their neighbourhood and whether they were thinking of moving house, 1 year previously. Unsurprisingly, the responses to these variables were highly significant and the estimated coefficients had the expected signs. Men and women who reported that they liked their neighbourhood were respectively $0.386 \log$-points and 0.317 log-points less likely to move than those who did not, whereas men and women who expressed a desire to move were respectively 0.783 log-points and $0.893 \log$-points more likely to move than those who expressed no such intention. The fact that intentions to migrate have a direct influence on actual migrations suggests that, in aggregate at least, there is some degree of labour market mobility in Britain, whereas the significant role for neighbourhood characteristics emphasizes the importance of non-labour market factors in affecting rates of mobility.

\section{Moving between local authority districts}

Thus far we have investigated migrations between the 11 standard statistical regions of Great Britain. Our regional focus was motivated by policy concerns about differences in labour market outcomes and hence welfare in different regions of the country. Our analysis begs the question, however, of whether regional migrations are different from other types of move which individuals might make, or whether the same influences apply to each type of change of residence. This could potentially be useful information for policy makers who might want to encourage regional migration to help to reduce economic disparities between geographically distinct areas of the country. Of course, moves between areas that are defined at a lower level of disaggregation are of some interest in their own right; however, our primary interest is in establishing the robustness of our regional results.

In this section, we report what happens when we re-estimate our duration model for 'moves' between two local authority districts and compare the results with migrations between regions. Table 7 compares moves with migrations in the raw data. In column (1) of Table 7, we can see the same 1229 migrations as in Table 1. Column (2) of Table 7 shows the 2639 individuals who move between two local authority districts but stay in the same region. The sum of these two columns is the 3868 spells which end in the moves that we are modelling.

Table 8 repeats Table 2 for moves between local authority districts. Here, 1158 males and 1283 females move between local authority districts, giving raw hazards of $18.36 \%$ and $19.48 \%$ for males and females respectively. These raw hazards are much higher than for regional migrations 
Table 7. Moves and migrations $\dagger$

\begin{tabular}{|lrrrr|}
\hline Region & (1) & (2) & (3) & \multicolumn{1}{c|}{$n_{r}$} \\
\hline London and South East & 363 & 1146 & 26343 & 27852 \\
South West & 146 & 273 & 8269 & 8688 \\
East Anglia & 69 & 111 & 3831 & 4011 \\
East Midlands & 124 & 235 & 7954 & 8313 \\
West Midlands & 105 & 153 & 7894 & 8152 \\
North West & 119 & 220 & 9356 & 9695 \\
Yorkshire and Humber & 122 & 160 & 8755 & 9037 \\
North East & 76 & 109 & 5507 & 5692 \\
Wales & 38 & 35 & 4594 & 4667 \\
Scotland & 67 & 197 & 7714 & 7978 \\
Total & 1229 & 2639 & 90217 & 94085 \\
& & & & \\
\hline
\end{tabular}

$\dagger$ Column (1) reports migrations from the region listed; column (2) reports moves within a region, but between two local authority districts; column (3) reports either moves between local authority districts or person-years where individuals stay put; $n_{r}$ is the sample size for each region, and equals (1) $+(2)+(3)$.

Table 8. Summary information: moves between local authority districts

\begin{tabular}{|lrr|}
\hline & Males & Females \\
\hline Number of moves $(a)$ & 1828 & 1985 \\
Number of movers $(b)$ & 1158 & 1283 \\
Sample size (person-years) $(c)$ & 44387 & 49698 \\
Sample size (persons) $(d)$ & 6308 & 6587 \\
Move rate (person-years) $(a / c)$ & 4.12 & 3.99 \\
Move rate $(b / d)$ & 18.35 & 19.48 \\
Number of completed spells $(e)$ & 5685 & 5856 \\
Number of censored spells $(f)$ & 2361 & 2614 \\
Left-truncated first spell $(g)$ & 3364 & 3708 \\
Flow subsample $(h)$ & 4682 & 4762 \\
Number of spells $(e+f=g+h)$ & 8046 & 8470 \\
& & \\
\hline
\end{tabular}

because many individuals move between local authority districts, but not between regions. Also note that the number of spells is larger, as there are $16516 / 12895=1.28$ spells per individual in a local authority district compared with 1.12 spells in a region.

Table 9 reports our estimates, and should be compared directly with Table 4 . Three things stand out. First, the basic shape of the non-parametric hazards can still be modelled as a Weibull distribution (see Fig. 2(c) and Fig. 2(d)). When repeating the test of the 15 restrictions that one imposes on a non-parametric hazard to generate a Weibull distribution, the $p$-values are 0.055 for both genders. Second, the degree of duration dependence in the data is almost the same for migrations as it is for moves (Table 10). To be precise, there is slightly less duration dependence for migrations compared with moves in both raw data and when we control for observables and unobservables. However, in no case is the difference significant. Clearly, the degree to which people become increasingly more attached to a location is not greatly affected by the level of 
Table 9. Hazard to moving local authority district; Weibull baseline hazard, Gaussian mixingt

\begin{tabular}{|c|c|c|c|c|}
\hline \multirow{2}{*}{$\begin{array}{l}\text { Variable } \\
\text { Weibull } \alpha\end{array}$} & \multicolumn{2}{|c|}{ Estimate for males } & \multicolumn{2}{|c|}{ Estimate for females } \\
\hline & 0.823 & $(0.035)$ & 0.872 & $(0.035)$ \\
\hline Age $18-19$ years & 0.202 & $(0.220)$ & -0.028 & $(0.187)$ \\
\hline Age $20-23$ years & 0.448 & $(0.201)$ & 0.073 & $(0.172)$ \\
\hline Age 24-29 years & 0.383 & $(0.204)$ & -0.117 & $(0.174)$ \\
\hline Age $30-37$ years & 0.171 & $(0.207)$ & -0.406 & $(0.180)$ \\
\hline Age $38-49$ years & -0.283 & $(0.214)$ & -0.799 & $(0.188)$ \\
\hline Age $\geqslant 50$ years & -0.540 & $(0.233)$ & -1.215 & $(0.210)$ \\
\hline Owned with mortgage & 0.082 & $(0.095)$ & -0.175 & $(0.088)$ \\
\hline Local authority rented & 0.222 & $(0.116)$ & -0.312 & $(0.106)$ \\
\hline Private unfurnished & 0.768 & $(0.124)$ & 0.200 & $(0.117)$ \\
\hline Private furnished & 0.833 & $(0.113)$ & 0.433 & $(0.110)$ \\
\hline Employed non-manual & 0.364 & $(0.066)$ & 0.100 & $(0.075)$ \\
\hline Unemployed & 0.222 & $(0.099)$ & 0.273 & $(0.116)$ \\
\hline Maternity or family care & 1.303 & $(0.175)$ & 0.304 & $(0.089)$ \\
\hline Higher degree & 0.873 & $(0.171)$ & 1.058 & $(0.171)$ \\
\hline Degree & 0.688 & $(0.114)$ & 0.883 & $(0.107)$ \\
\hline A level & 0.594 & $(0.109)$ & 0.659 & $(0.107)$ \\
\hline General Certificate of Secondary Education & 0.311 & $(0.105)$ & 0.365 & $(0.097)$ \\
\hline 1 child & -0.169 & $(0.077)$ & -0.188 & $(0.068)$ \\
\hline 2 or 3 children & -0.182 & $(0.094)$ & -0.236 & $(0.085)$ \\
\hline$\geqslant 4$ children & -0.232 & $(0.139)$ & -0.215 & $(0.122)$ \\
\hline Like to move & 0.906 & $(0.055)$ & 1.016 & $(0.054)$ \\
\hline Like neighbourhood & -0.366 & $(0.075)$ & -0.438 & $(0.069)$ \\
\hline Spouse employed full time & -0.280 & $(0.071)$ & -0.256 & $(0.060)$ \\
\hline Spouse employed part time & -0.394 & $(0.099)$ & -0.152 & $(0.166)$ \\
\hline Spouse unemployed & -0.090 & $(0.087)$ & -0.242 & $(0.089)$ \\
\hline Constant & -3.982 & $(0.258)$ & -2.872 & $(0.228)$ \\
\hline & 0.841 & $(0.047)$ & 0.822 & $(0.046)$ \\
\hline & & & & \\
\hline Log-likelihood & -65 & 596 & -7 & 3.056 \\
\hline
\end{tabular}

$\dagger$ See the footnotes to Table 4 .

Table 10. Estimates of the Weibull parameter

\begin{tabular}{|c|c|c|c|c|}
\hline & \multicolumn{2}{|c|}{$\begin{array}{l}\text { Estimates for } \\
\text { migrations }\end{array}$} & \multicolumn{2}{|c|}{$\begin{array}{c}\text { Estimates for } \\
\text { moves }\end{array}$} \\
\hline & Males & Females & Males & Females \\
\hline Raw & 0.372 & 0.351 & 0.369 & 0.294 \\
\hline Age only & 0.490 & 0.498 & 0.485 & 0.458 \\
\hline Full covariate vector & 0.630 & 0.610 & 0.640 & 0.586 \\
\hline Full covariate vector plus Gaussian mixing & 0.863 & 0.857 & 0.823 & 0.772 \\
\hline
\end{tabular}

geographical aggregation. This finding, which we believe to be not widely known, suggests that, perhaps not surprisingly, inertia is driven more by factors relating to the individual's immediate location, the local authority district, rather than factors of the wider location, the region.

The third noticeable feature is that the parameter estimates in Table 9 are very similar to those in Table 4. In short, all of the discussion in Section 4.3 about why certain individuals are 
more likely to migrate between regions applies to moves between local authority districts; it is the reasons why individuals move that are important rather than the distance that they end up moving.

\section{Conclusion}

The process of individual migration is naturally and logically considered as the termination, or otherwise, of spells of residence in a particular locale. The unavailability of longitudinal data sets that follow individuals over long periods of time has prevented migration being modelled in this way. To understand the migration process, we model, for the first time using British data, the hazard to regional migration. The data set that we use, the BHPS 1991-2007, uniquely allows us to exploit retrospective information on residency. Thus, our methodology addresses so-called late entry, as well as the more familiar issue of unobserved heterogeneity. The latter is statistically significant and failing to account for it would lead to spurious estimates of duration dependence.

We find that the baseline hazard can be adequately characterized by a Weibull density function. In the raw data, the Weibull $\alpha$ is estimated at about 0.36 and rises to about 0.86 when we control for observable and unobservable characteristics. Because 0.86 is significantly smaller than 1 , it is the case that the longer individuals stay in a region the less likely they are to migrate to another region of the UK. We identify the process of growing older as a particularly important reason for why this happens. With an aging population, this implies that, other things equal, regional labour mobility in the future is likely to be reduced, and it is unlikely to be the case that the migration of labour will be sufficient to reduce interregional labour market inequalities.

Similarly, we would expect to observe, in the aggregate, net flows from 'poorer' regions to 'better' regions. As with the existing literature, we attempt to capture these regional effects by constructing a regional labour market tightness variable and a regional real wage, but we find that the effects are unrobust and insignificant. Thus we illustrate that very little is learned from this 'traditional' approach to modelling migrations. Our approach is new in this literature. We divide individuals who migrate into two types, namely those who move to a region with a higher real wage and those who move to a region with a lower real wage. Thus we have a competing risks duration model. The same approach can be used for migrations to and from regions with higher or lower labour market tightness. Again, we find little evidence that regional variables have an effect, although there may be some effect, at the borderline of statistical significance, for workers with particular characteristics, e.g. whether individuals — but more so males - have a manual or non-manual occupation.

The finding that real wages and tightness, measured at the regional level, do not have a strong influence on individual migration decisions requires some discussion, not least because it contradicts the findings of some previous studies of Great Britain. In part it may reflect our duration methodology which, we would argue, provides a better representation of the process of regional migration. However, it may be that the characteristics of labour markets measured at the regional level genuinely do not influence individual decisions whereas those measured at some different level do. For example, subregional labour markets (those in large towns and cities which attract large-scale commuting), or labour markets that are defined over particular skill or occupation groups, may be more relevant to individuals who are considering migration.

When we analyse who moves, our results confirm that the highly educated are more mobile, and the trend towards a better qualified workforce may work to offset the effect of an aging population on rates of migration. We also find that gender differences are important, notably 
where there are children in the household. In contrast with other studies, housing tenure is not found to act as a brake on labour migration, which may reflect the changes in house prices and levels of home ownership and council tenancy over the period that we consider. It is also worth noting that neither the effects of individual characteristics nor the degree of duration dependence vary substantially with the distance moved. This suggests that there is nothing special about regional, as opposed to other types of, migration.

Motivating our study of regional migration in Britain is the underlying idea that labour markets work better when labour is mobile. Yet, our results, taken as a whole, provide little evidence that regional migration is likely to increase significantly over the short to medium term and hence that policy makers cannot rely on the migration of labour to reduce, seemingly persistent, economic inequalities between regions. A role for policy which redistributes resources between regions is therefore supported. One caveat to this is the increased levels of international labour migration which Britain has experienced in recent times. It remains an open question how international and internal migration interact, and how this affects the operation of labour markets and the evolution of interregional inequality.

\section{Acknowledegements}

The BHPS data were made available through the Economic and Social Research Council Data Archive. The data were originally collected by the Economic and Social Research Council Research Centre on Micro-Social Change at the University of Essex (now incorporated within the Institute for Social and Economic Research). Neither the original collectors of the data nor the Archive bear any responsibility for the analyses or interpretations that are presented here. The authors thank both organizations for providing access to the data. William Whittaker thanks the Economic and Social Research Council for his Postgraduate Studentship under reference PTA-030-2003-01656 for his studies at the University of Manchester. The comments of participants at the 2009 Royal Economic Society Annual Conference (Surrey) are gratefully acknowledged, as are those of Mette Christensen, Stephen Jenkins, Mark Taylor, the Associate Editor and a referee. The comments of the Joint Editor were particularly helpful. The usual disclaimer applies.

\section{Appendix A: Competing risks}

Competing risks models are easily estimated, because the exit state, here migration, is simply split into $R$ different states, and parameters are estimated on a differently constructed data set for each state. It is less well known how the hazards should be interpreted. In this exposition, we use continuous time versions of Weibull hazards for $R=2$. It draws heavily on Lancaster (1990), example 9, page 105, and Thomas (1996). To distinguish discrete elapsed duration $a$ in the main text, here we use $t$ to denote continuously measured elapsed duration.

The hazard (or transition intensity) to exit to $r$ is given by

$$
h_{r}(t ; \mathbf{x})=\alpha_{r} \gamma_{r} t^{\alpha_{r}-1} \exp \left(\mathbf{x}^{\prime} \boldsymbol{\beta}_{r}\right), \quad r=1,2 .
$$

To ease exposition, note that the unobserved heterogeneity terms are averaged to 0 . Ignoring the covariates $\left(\boldsymbol{\beta}_{r}=0\right)$, Fig. 4 plots the case where the first hazard exhibits negative duration dependence $\left(\alpha_{1}<1\right)$ and the other positive duration dependence $\left(\alpha_{2}>1\right)$. At $t^{*}$, the individual is equally likely to exit to either state, $h_{1}\left(t^{*}\right)=h_{2}\left(t^{*}\right)$.

Two summary measures of interest are the unconditional probability of departure to $r, \Pi_{r}$, and the average waiting time before exiting to $r, E_{r}$. These require formulae for the overall hazard, which is given by

$$
h(t ; \mathbf{x})=\alpha_{1} \gamma_{1} t^{\alpha_{1}-1} \exp \left(\mathbf{x}^{\prime} \boldsymbol{\beta}_{1}\right)+\alpha_{2} \gamma_{2} t^{\alpha_{2}-1} \exp \left(\mathbf{x}^{\prime} \boldsymbol{\beta}_{2}\right),
$$

and the corresponding survivor function $S(t ; \mathbf{x})$, which is given by 


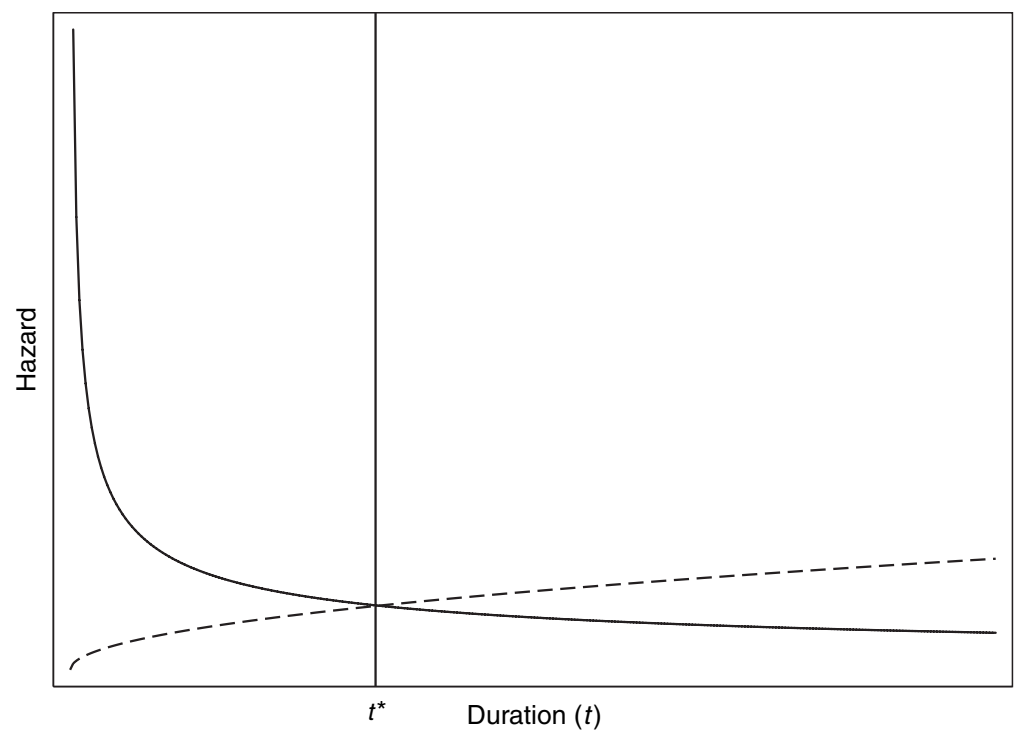

Fig. 4. Two Weibull hazards:,$- h_{1}(\alpha<1) ;---, h_{2}(\alpha>1)$

$$
\begin{aligned}
S(t ; \mathbf{x}) & =\exp \left\{-\int_{0}^{t} h(s ; \mathbf{x}) \mathrm{d} s\right\} \\
& =\exp \left\{-\int_{0}^{t} \alpha_{1} \gamma_{1} s^{\alpha_{1}-1} \exp \left(\mathbf{x}^{\prime} \boldsymbol{\beta}_{1}\right)+\alpha_{2} \gamma_{2} s^{\alpha_{2}-1} \exp \left(\mathbf{x}^{\prime} \boldsymbol{\beta}_{2}\right) \mathrm{d} s\right\} \\
& =\exp \left\{-\left[\gamma_{1} s^{\alpha_{1}} \exp \left(\mathbf{x}^{\prime} \boldsymbol{\beta}_{1}\right)+\gamma_{2} s^{\alpha_{2}} \exp \left(\mathbf{x}^{\prime} \boldsymbol{\beta}_{2}\right)\right]_{0}^{t}\right\} \\
& =\exp \left\{-\gamma_{1} t^{\alpha_{1}} \exp \left(\mathbf{x}^{\prime} \boldsymbol{\beta}_{1}\right)-\gamma_{2} t^{\alpha_{2}} \exp \left(\mathbf{x}^{\prime} \boldsymbol{\beta}_{1}\right)\right\} \equiv S_{1}(t ; \mathbf{x}) S_{2}(t ; \mathbf{x}) .
\end{aligned}
$$

The overall survivor function $S(t ; \mathbf{x})$ depends on the parameters of both hazards. It follows that the same applies to the unconditional probability of departure to $r$,

$$
\begin{aligned}
\pi_{r} & =\int_{0}^{\infty} S(s ; \mathbf{x}) h_{r}(s ; \mathbf{x}) \mathrm{d} s \\
& =\alpha_{r} \gamma_{r} \exp \left(\mathbf{x}^{\prime} \boldsymbol{\beta}_{r}\right) \int_{0}^{\infty} s^{\alpha_{r}-1} \exp \left\{-\gamma_{1} s^{\alpha_{1}} \exp \left(\mathbf{x}^{\prime} \boldsymbol{\beta}_{1}\right)-\gamma_{2} s^{\alpha_{2}} \exp \left(\mathbf{x}^{\prime} \boldsymbol{\beta}_{2}\right)\right\} \mathrm{d} s
\end{aligned}
$$

and the average waiting time in the state conditional on exiting to $r$,

$$
\begin{aligned}
E_{r} & =\left(\pi_{r}\right)^{-1} \int_{0}^{\infty} s S(s) h_{r}(s) \mathrm{d} s \\
& =\left(\pi_{r}\right)^{-1} \alpha_{r} \gamma_{r} \exp \left(\mathbf{x}^{\prime} \boldsymbol{\beta}_{r}\right) \int_{0}^{\infty} s^{\alpha_{r}} \exp \left\{-\gamma_{1} s^{\alpha_{1}} \exp \left(\mathbf{x}^{\prime} \boldsymbol{\beta}_{1}\right)-\gamma_{2} s^{\alpha_{2}} \exp \left(\mathbf{x}^{\prime} \boldsymbol{\beta}_{2}\right)\right\} \mathrm{d} s .
\end{aligned}
$$

Moreover, all three formulae must be calculated by numerical integration. As Thomas (1996) noted,

'the estimated qualitative effect of a covariate on the hazard for risk $r$ typically conveys no information on its qualitative effect on either the likelihood of, or expected time until, exit via $r$ '.

Thomas then suggested that a better measure to analyse is the probability of departure to $r$ given departure at elapsed duration $t$, which is given by

$$
P_{r}(t ; \mathbf{x})=\frac{h_{r}(t ; \mathbf{x})}{h_{1}(t ; \mathbf{x})+h_{2}(t ; \mathbf{x})}, \quad \quad r=1,2 .
$$




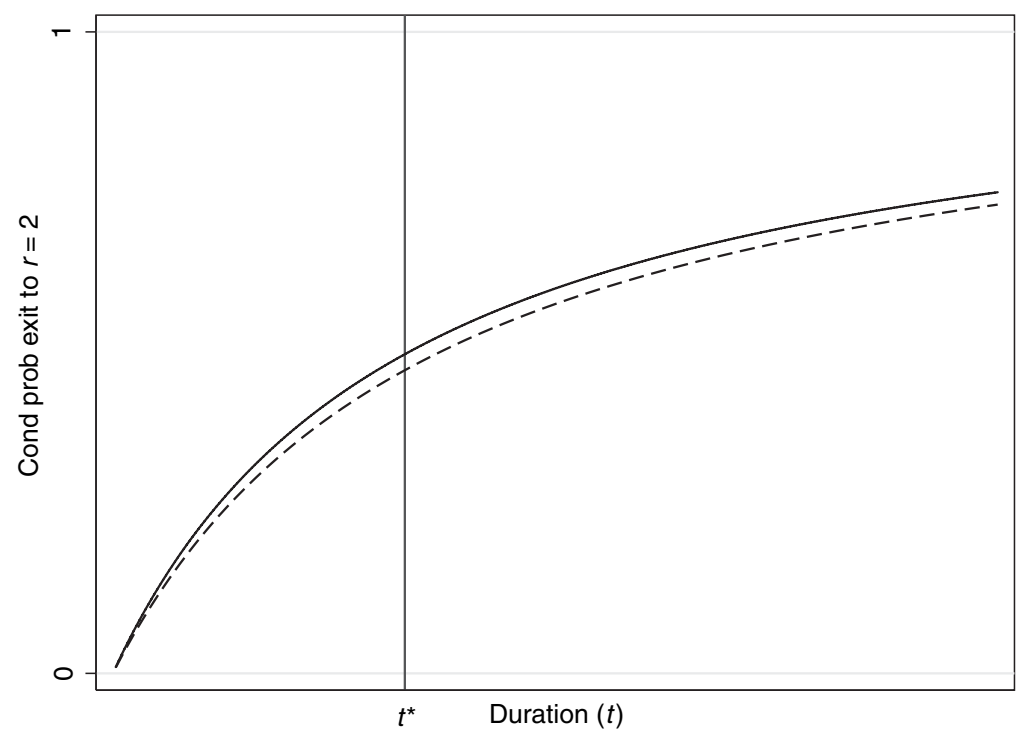

Fig. 5. Two (Weibull) hazards $\left(-, P_{2}(x=0) ;---, P_{2}(x=1)\right)$ : probability of departure to $r=2$ given departure at elapsed duration $t$

This is equation (10) of the main text. Thomas noted that if we make the proportional hazards assumption, rather than the more restricted Weibull assumption,

$$
h_{r}(t)=\bar{h}_{r}(t) \exp \left(\mathbf{x}^{\prime} \boldsymbol{\beta}_{r}\right), \quad r=1,2,
$$

where $\bar{h}_{r}(t)$ is any parametric or non-parametric baseline hazard, then we can sign the derivative of the effect of any covariate $x$ on $P_{r}$. Indeed, we can compute these marginal effects,

$$
\frac{\partial P_{2}(t)}{\partial x}=\frac{\left(\beta_{2}-\beta_{1}\right) h_{1} h_{2}}{\left(h_{1}+h_{2}\right)^{2}}=-\frac{\partial P_{1}(t)}{\partial x} .
$$

This is equation (11) of the main text. It should be noted that when one uses discrete data, one is making use of the same approximation that allows equation (5) to be interpreted as equation (6). In other words, the effects of continuous covariates, equation (11), and dummy covariates, equation (12), can be interpreted in the usual way. Because the probabilities sum to 1 , across $r$, these marginal effects sum to 0 . To examine whether there is a qualitative effect, one just tests $H_{0}: \beta_{1}=\beta_{2}$. To test whether the marginal effect is 0 , the estimated standard error can be computed by using equation (13) in the main text.

Returning to the Weibull case, $P_{2}(t)$, the probability of exit to state 2, for the hazards drawn in Fig. 4, is an upward sloping monotone function. See Fig. 5. This is because it has the same shape as $h_{2}(t) . t^{*}$ corresponds to where $P_{2}(t)=h_{2}(t) / h(t)=\frac{1}{2}$. The effect of switching a binary covariate on and off is also shown.

\section{References}

Andrews, M., Bellmann, L., Schank, T. and Upward, R. (2007) Foreign-owned plants and job security. Discussion Paper 07/36. Centre for Globalisation and Labour Markets, University of Nottingham, Nottingham.

Angrist, J. and Pischke, J.-S. (2009) Mostly Harmless Econometrics: an Empiricist's Companion. Princeton: Princeton University Press.

Annual Survey of Hours and Earnings (2009) The Annual Survey of Hours and Earnings 1997-2007. Office for National Statistics, London.

van den Berg, G. (2001) Duration models: specification, identification, and multiple durations. In Handbook of Econometrics, vol. 5 (eds J. Heckman and E. Leamer), pp. 3381-3460. Amsterdam: North-Holland.

Boheim, R. and Taylor, M. (2002) Tied down or room to move?: investigating the relationships between housing tenure, employment status and residential mobility in Britain. Scot. J. Polit. Econ., 49, 369-392. 
British Household Panel Survey (2006) Data files and associated documentation. Data Archive and the Economic and Social Research Council Research Centre on Micro-Social Change, Colchester.

Buck, N. (2000) Economic change: the uses of household panel studies. In Researching Social and Economic Change (ed. D. Rose), pp. 250-272. London: Routledge.

Cameron, C. and Trivedi, P. (2005) Microeconometrics: Methods and Applications. Cambridge: Cambridge University Press.

Coleman, D. and Salt, J. (1992) The British Population: Patterns, Trends, and Processes. Oxford: Oxford University Press.

Detang-Dessendre, C. and Molho, I. (1999) Migration and changing employment status: a hazard function analysis. J. Regl Sci., 39, 103-125.

Detang-Dessendre, C. and Molho, I. (2000) Residence spells and migration: a comparison for men and women. Urb. Stud., 37, 247-260.

Evans, P. and McCormick, B. (1994) The new pattern of regional unemployment: causes and policy significance. Econ. J., 104, 633-647.

Faggian, A., McCann, P. and Sheppard, S. (2007) Some evidence that women are more mobile than men: gender differences in UK graduate behaviour. J. Regl Sci., 47, 517-539.

Gerber, T. (2005) Internal migration dynamics in Russia, 1985-2001: determinants, motivations and consequences. Mimeo. University of Wisconsin-Madison, Madison.

Guo, G. (1993) Event-history analysis for left-truncated data. In Sociological Methodology (ed. P. Marsden), pp. 217-243. Cambridge: Blackwell.

Haapanen, M. and Tervo, H. (2009) Cumulative inertia or cumulative stress?: migration behaviour of Finnish Graduates. Migrn Lett., 6, 83-90.

Halifax Building Society (2009) Halifax house price index 1991-2007. Halifax Building Society, London.

Han, A. and Hausman, J. (1990) Flexible parametric estimation of duration and competing risk models. J. Appl. Econmetr., 5, 1-28.

Heckman, J. and Singer, B. (1984) Econometric duration analysis. J. Econmetr., 24, 63-132.

Hughes, G. and McCormick, B. (1981) Do council house policies reduce migration between regions? Econ. J., 91, 919-937.

Hughes, G. and McCormick, B. (1985) Migration intentions in the UK: which households want to migrate and which succeed? Econ. J., 95, suppl., 113-123.

Hughes, G. and McCormick, B. (1994) Did migration in the 1980s narrow the North-South divide? Economica, 61, 509-527.

Jackman, R. and Savouri, S. (1992) Regional migration in Britain: an analysis of gross flows using NHS Central Register data. Econ. J., 102, 1433-1450.

Jenkins, S. (2005) Survival analysis. Manuscript. Institute for Social and Economic Research, University of Essex, Colchester.

Lancaster, T. (1990) The Econometric Analysis of Transition Data. Cambridge: Cambridge University Press.

McCormick, B. (1997) Regional unemployment and labour mobility in the UK. Eur. Econ. Rev., 41, 581-589.

Meyer, D. (1990) Unemployment insurance and unemployment spells. Econometrica, 58, 757-782.

Moulton, B. (1986) Random group effects and the precision of regression estimates. J. Econmetr., 12, 385-397.

New Earnings Survey (2009) The New Earnings Survey 1991-2001. Office for National Statistics, London.

NOMISWEB (2009) Job Centre Plus notified vacancies 1991-2007. In NOMIS Official Labour Market Statistics. London: Office for National Statistics.

Office for National Statistics (2009) Estimates of claimant count 1991-2007. Office for National Statistics, London.

Oswald, A. (1997) The missing piece of the unemployment puzzle. Inaugural lecture. Department of Economics, University of Warwick, Coventry.

Pissarides, C. and Wadsworth, J. (1989) Unemployment and the inter-regional mobility of labour. Econ. J., 99, 739-755.

Steele, F., Goldstein, H. and Browne, W. (2004) A general multilevel multistate competing risks model for event history data, with an application to a study of contraceptive use dynamics. Statist. Modllng, 4, 145-159.

Steele, F., Kallis, C. and Joshi, H. (2006) The formation and outcomes of cohabiting and marital partnerships in early adulthood: the role of previous partnership experience. J. R. Statist. Soc. A, 169, 757-779.

Taylor, M., Brice, J., Buck, N. and Prentice-Lane, E. (2009) British Household Panel Survey User Manual, vol. A, Introduction, Technical Report and Appendices. Colchester: University of Essex.

Thomas, J. (1996) On the interpretation of covariate estimates in independent competing-risks models. Bull. Econ. Res., 48, 27-39.

Wooldridge, J. (2002) Econometric Analysis of Cross Section and Panel Data. Cambridge: MIT Press. 